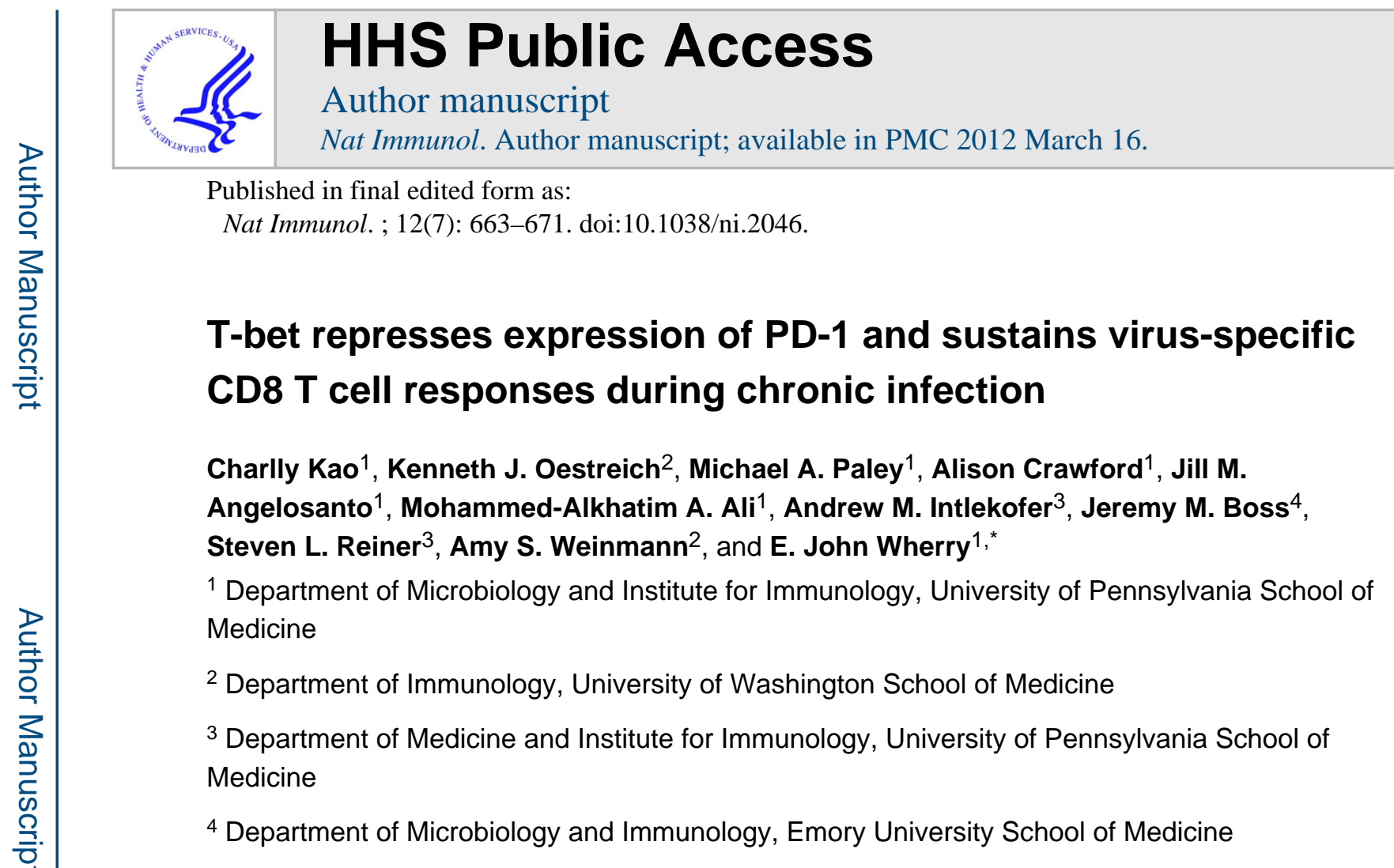

\begin{abstract}
$\mathrm{T}$ cell exhaustion plays a major role in failure to control chronic infections. High expression of inhibitory receptors, including PD-1, and the inability to sustain functional $\mathrm{T}$ cell responses contribute to exhaustion. However, the transcriptional control of these processes remains unclear. Here we demonstrate that the transcription factor T-bet regulates $\mathrm{CD} 8^{+} \mathrm{T}$ cell exhaustion and inhibitory receptor expression. T-bet directly repressed $P d c d l$ transcription and decreased the expression of other inhibitory receptors. While elevated T-bet promoted terminal differentiation following acute infection, high T-bet expression sustained exhausted $\mathrm{CD} 8^{+} \mathrm{T}$ cells and repressed inhibitory receptor expression during chronic viral infection. Persisting antigenic stimulation caused T-bet downregulation, which resulted in more severe exhaustion of $\mathrm{CD} 8^{+} \mathrm{T}$ cells. These observations suggest therapeutic opportunities involving increasing T-bet expression during chronic infection.
\end{abstract}

\title{
The Introduction
}

$\mathrm{CD} 8^{+} \mathrm{T}$ cells play a crucial role in the eradication of many intracellular infections and can provide potent protective immunity. Following acute infection or vaccination, antigenspecific effector $\mathrm{CD} 8^{+} \mathrm{T}$ cells acquire and maintain the potential to efficiently perform

\footnotetext{
Users may view, print, copy, download and text and data- mine the content in such documents, for the purposes of academic research, subject always to the full Conditions of use: http://www.nature.com/authors/editorial_policies/license.html\#terms

*Address for Correspondence: Dr. E John Wherry, 421 Curie Blvd, Room 312, University of Pennsylvania, Philadelphia, PA 19104, Wherry@mail.med.upenn.edu.

Competing financial interests

EJW has a patent licensing agreement on the PD-1 pathway.

Author Contributions

C.K. and E.J.W. designed the experiments and analyzed the data; K.J.O. performed ChIP for CD4 T cells and EL4 luciferase assays; A.C., J.M.A., M.A.P, M.A.A, and A.M.I. assisted in performing and analyzing experiments; J.M.B., S.L.R, and A.S.W. assisted with the design of the experiments as well as providing constructs, reagents, and mice strains; C.K. and E.J.W. wrote the manuscript.
} 
functions including cytokine production and cytotoxicity, as well as the ability to rapidly proliferate and expand in number upon antigen re-exposure ${ }^{1}$. These memory $\mathrm{CD} 8^{+} \mathrm{T}$ cells are also maintained for long periods without antigen by interleukin 7 (IL-7) and IL-15 ${ }^{1}$. In contrast, during chronic infections, virus-specific $\mathrm{CD} 8^{+} \mathrm{T}$ cells become dysfunctional and fail to form optimal memory cells. These "exhausted" $\mathrm{CD} 8^{+} \mathrm{T}$ cells require antigen for survival and no longer use IL-7 or IL-15 efficiently ${ }^{2}$. The loss of $\mathrm{CD} 8^{+} \mathrm{T}$ cell function during chronic viral infection is a stepwise process, where the ability to make IL-2, TNF, IFN $-\gamma$ and $\beta$-chemokines is progressively lost as the cells become more exhausted ${ }^{2}$. Defects in proliferation, cytotoxicity and survival are also characteristics of exhausted CD8 ${ }^{+} \mathrm{T}$ cells $^{2}$. In the most severe instances of exhaustion, which occur when viral or antigen load is high, virus-specific $\mathrm{CD} 8^{+} \mathrm{T}$ cells can be physically deleted ${ }^{2}$. $\mathrm{CD}^{+} \mathrm{T}$ cell exhaustion is observed in mice during chronic lymphocytic choriomeningitis virus (LCMV) infection and other persisting viral infections, in primate models during SIV infections and in humans during chronic viral infections such as HIV, HCV and HBV or cancer ${ }^{2}$.

Cell surface inhibitory receptors have a major role in regulating $\mathrm{T}$ cell exhaustion during chronic infection. Expression of PD-1 ( $P d c d 1)$, an inhibitory receptor of the CD28-CTLA-4 family, is dramatically upregulated and its high expression is sustained during chronic LCMV infection in mice ${ }^{3,4}$. Blocking the PD-1 signaling pathway in vivo reinvigorates exhausted $\mathrm{CD}^{+} \mathrm{T}$ cell responses, leading to enhanced control of viral replication ${ }^{3}$. These LCMV mouse model observations were also confirmed in humans, where PD-1 pathway blockade enhanced HIV and HCV-specific T cell responses in vitro and improved the outcome of SIV infection in macaques by reducing viral burden and prolonging survival ${ }^{2}$. Recent studies also suggest an important role for the PD-1 pathway in tumors immunity 5,6 and early clinical trials blocking the PD-1 pathway in cancer patients are showing promise ${ }^{7}$.

In addition to $\mathrm{PD}-1$, exhausted $\mathrm{CD} 8^{+} \mathrm{T}$ cells upregulate many other inhibitory cell surface receptors, including LAG-3, CD244, CD160, CTLA-4, and Tim- $3{ }^{4,8}, 9$. These receptors have cooperative effects in mediating $\mathrm{CD} 8^{+} \mathrm{T}$ cell dysfunction. Simultaneous blockade of PD-1 with Lag-3 or Tim-3 is substantially better at reversing CD8 ${ }^{+} \mathrm{T}$ cell dysfunction and reducing viral burden than blocking each pathway alone during chronic infection in mice ${ }^{8,10}$ and in vitro data from humans is consistent with these observations ${ }^{11}$. The underlying mechanisms controlling the expression of these inhibitory pathways during chronic viral infections, however, remain poorly understood.

Comparison of gene expression profiling in exhausted and effector or memory $\mathrm{CD} 8^{+} \mathrm{T}$ cells from mice revealed substantial changes in many pathways ${ }^{4}$. In addition to inhibitory receptors, exhausted $\mathrm{CD} 8^{+} \mathrm{T}$ cells have an altered expression of transcription factors and other genes involved in transcriptional regulation. Blimp-1 expression is especially high in exhausted $\mathrm{CD} 8^{+} \mathrm{T}$ cells ${ }^{12}$ and promotes expression of inhibitory receptors including PD-1, LAG-3, CD160 and CD244. During acute infection, Blimp-1 promotes terminal differentiation of effector $\mathrm{CD} 8^{+} \mathrm{T}$ cells towards the CD127 ${ }^{\mathrm{Lo}} \mathrm{KLRG}-1^{\mathrm{Hi}}$ subset instead of CD127 ${ }^{\mathrm{Hi}}$ KLRG- $1{ }^{\mathrm{Lo}}$ memory precursors ${ }^{13,}{ }^{14}$. Thus, Blimp-1 appears to repress memory $\mathrm{CD}^{+} \mathrm{T}$ cell formation and promote terminal differentiation during both acute and chronic viral infection. 
Like Blimp-1, high T-bet expression promotes formation of terminally differentiated CD $127^{\text {Lo }}$ KLRG- ${ }^{\mathrm{Hi}}$ effector CD $8^{+} \mathrm{T}$ cells, while the CD12 $7^{\mathrm{Hi}} \mathrm{KLRG}-1^{\mathrm{Lo}}$ memory precursors express lower amounts of T-bet. Inflammation is an important factor driving high T-bet expression, and therefore $\mathrm{T}$ cell terminal differentiation, during acute infection ${ }^{15}$. In the absence of T-bet, effector $\mathrm{CD} 8^{+} \mathrm{T}$ cells are mostly CD127 ${ }^{\mathrm{Hi}} \mathrm{KLRG}-1^{\mathrm{Lo}}$ and become memory $\mathrm{CD}^{+}{ }^{+} \mathrm{T}$ cells with enhanced recall responses ${ }^{16}$. Thus, in acute infection, T-bet and Blimp-1 have similar (and perhaps partially overlapping) roles in promoting effector function and terminal differentiation of $\mathrm{CD} 8^{+} \mathrm{T}$ cells.

In this study we examined the role of T-bet in regulating virus-specific $\mathrm{CD} 8^{+} \mathrm{T}$ cell responses during chronic viral infection. We show a critical role for $\mathrm{T}$-bet in $\mathrm{CD} 8^{+} \mathrm{T}$ cell exhaustion, which is distinctly different from its role in acute infection. T-bet expression was downregulated in exhausted $\mathrm{CD} 8^{+} \mathrm{T}$ cells in response to persisting antigen, and expression of T-bet was inversely correlated with expression of a subset of inhibitory receptors, including PD-1. Genetic ablation of T-bet exacerbated $\mathrm{CD} 8^{+} \mathrm{T}$ cell exhaustion and increased viral load. Conversely, overexpression of T-bet improved the fitness of exhausted CD ${ }^{+} \mathrm{T}$ cells and reduced the expression of PD- 1 and other inhibitory receptors. T-bet bound directly to a regulatory region upstream of the $P d c d l$ transcriptional start site. Thus, during chronic viral infection, $\mathrm{T}$-bet regulates $\mathrm{CD} 8^{+} \mathrm{T}$ cell exhaustion by sustaining $\mathrm{CD}^{+} \mathrm{T}$ cell responses and by repressing the expression of PD- 1 and other inhibitory receptors.

\section{Results}

\section{T-bet expression in chronic and acute infection}

To examine the role of T-bet in $\mathrm{CD} 8^{+} \mathrm{T}$ cells during chronic viral infection we compared $\mathrm{T}$ bet expression in mice infected with either LCMV Armstrong (Arm) that is cleared within 8-10 days post-infection (p.i.), or LCMV clone 13, that induces 2-3 months of viremia and persists long-term in some tissues. One set of clone 13 infected mice was transiently depleted of $\mathrm{CD}^{+}{ }^{+} \mathrm{T}$ cells prior to infection, a treatment that exacerbates viral load and $\mathrm{CD} 8^{+}$ $\mathrm{T}$ cell exhaustion ${ }^{8}$. All CD $44^{\text {hi }} \mathrm{CD}^{+} \mathrm{T}$ cells showed higher T-bet expression compared to $\mathrm{CD} 44^{\text {lo }} \mathrm{CD} 8^{+} \mathrm{T}$ cells (Supplementary Fig. 1). No T-bet staining was detected in $\mathrm{CD} 8^{+} \mathrm{T}$ cells from T-bet knockout (KO) mice (Supplementary Fig. 1). T-bet expression was reduced in LCMV-tetramer ${ }^{+} \mathrm{CD} 8^{+} \mathrm{T}$ cells from clone 13 compared to Arm infected mice (Fig. 1a). To determine whether this reduced T-bet expression was due to a defect in initial induction, we examined T-bet expression in antigen-specific $\mathrm{CD}^{+} \mathrm{T}$ cells on $\mathrm{d} 1-3$ p.i. using adoptively transferred TCR transgenic (P14) CD8 ${ }^{+} \mathrm{T}$ cells specific for the $\mathrm{D}^{\mathrm{b}} \mathrm{GP} 33$ epitope. On d1 and d3 p.i., T-bet expression was similar during Arm and clone 13 infection (Supplementary Fig. 2), suggesting that there were no gross differences in initial induction of T-bet in virusspecific $\mathrm{CD}^{+} \mathrm{T}$ cells. However, on day 8 p.i., cells from clone 13 infected mice expressed significantly lower amounts of T-bet (Fig. 1b). By d16 p.i., two distinct subsets of T-bet expressing tetramer ${ }^{+} \mathrm{CD} 8^{+} \mathrm{T}$ cells emerged during clone 13 infection, $\mathrm{T}-$ bet ${ }^{\mathrm{Bright}}$ and $\mathrm{T}$ bet $^{\text {Dim }}$ (Fig. 1b). The expression of T-bet in the T-bet ${ }^{\text {Bright }}$ group was similar to that observed during acute infection (Fig. 1b). Notably, virus-specific CD8 ${ }^{+} \mathrm{T}$ cells in the CD4depleted mice, were predominantly $\mathrm{T}$-bet ${ }^{\mathrm{Dim}}$. Thus, $\mathrm{T}$-bet was induced in virus-specific 
$\mathrm{CD} 8^{+} \mathrm{T}$ cells during chronic LCMV infection, but persistence of the infection corresponded to a substantial reduction in $\mathrm{T}$-bet expression in virus-specific $\mathrm{CD} 8^{+} \mathrm{T}$ cells compared to acute infection.

\section{Higher viral load and reduced CD8 ${ }^{+} \mathrm{T}$ cell responses without T-bet}

To examine the impact of reducing T-bet in $\mathrm{T}$ cells during chronic infection, we used mice in which one or both $T b x 21$ alleles were floxed and deleted in $\mathrm{CD} 4^{+}$and $\mathrm{CD} 8^{+} \mathrm{T}$ cells using CD4-Cre (cHet and cKO respectively). T-bet protein expression in $\mathrm{CD}^{+} \mathrm{T}$ cells from $\mathrm{cKO}$ mice was low or negative, intermediate in cHet mice and higher in $\mathrm{CD} 8^{+} \mathrm{T}$ cells from wildtype mice (Supplementary Fig. 3). There was no difference in the frequency of antigenspecific $\mathrm{CD} 8^{+} \mathrm{T}$ cells in the spleens from wild-type and cHet mice at d8 p.i. (Fig. 2a). The frequency of antigen-specific $\mathrm{CD} 8^{+} \mathrm{T}$ cells in the spleens of $\mathrm{cKO}$ mice was reduced compared to cHet and wild-type mice, resulting in a slight reduction in the absolute number on d8 p.i. in some (Fig. 2b), but not all (Supplementary Fig. 4) experiments. Overall, the breadth and immunodominance of the responses were similar between wild-type and cKO mice at d8 p.i. (Supplementary Fig. 4).

In T-bet-deficient mice, memory $\mathrm{CD} 8^{+} \mathrm{T}$ cells are maintained long-term following acute infection ${ }^{16}$. In contrast, by d 30 of clone 13 infection there was a severe reduction in the numbers of T-bet cKO antigen-specific $\mathrm{CD}^{+} \mathrm{T}$ cells in the spleen (Fig. 2b) and other tissues (Fig. 2c). cHet mice also had a significant reduction of virus-specific $\mathrm{CD} 8^{+} \mathrm{T}$ cells in the bone marrow and blood at $\mathrm{d} 30$ following clone 13 infection (Fig. 2c). A distinct population of $\mathrm{CD} 44^{\mathrm{hi}} \mathrm{CD} 8^{+} \mathrm{T}$ cells was still present in cKO mice (Fig. 2a), suggesting that the loss of $\mathrm{LCMV}$-specific $\mathrm{CD} 8^{+} \mathrm{T}$ cells did not result from a more general defect in all $\mathrm{CD} 8^{+} \mathrm{T}$ cells.

T-bet is not required for the clearance of LCMV Arm ${ }^{17}$. However, during clone 13 infection viremia was significantly elevated in cKO compared to wild-type mice, especially at later time points (Fig. 2d and e). Ablation of a single copy of T-bet also increased viral load, although this difference only became significant after $\sim 2$ months p.i. (Supplementary Fig. 5). These data suggest that $\mathrm{T}$-bet has a role in sustaining the virus-specific $\mathrm{CD} 8^{+} \mathrm{T}$ cell response during chronic LCMV infection.

We next examined the ability of $\mathrm{CD}^{+} \mathrm{T}$ cells to make cytokines upon antigen restimulation. While cKO antigen-specific $\mathrm{CD} 8^{+} \mathrm{T}$ cells were able to degranulate, $\sim 20 \%$ fewer T-bet cKO $\mathrm{CD}^{+} \mathrm{T}$ cells expressed granzyme $\mathrm{B}$ (data not shown). On d8 p.i., the amount of the cytokines and chemokines produced per cell (i.e. MFI) was similar in wild-type and T-bet deficient $\mathrm{CD}^{+} \mathrm{T}$ cells (Fig. 3a,b, data not shown). The percentage of IFN- $\gamma$ and MIP-1a coproducers was also similar $(\sim 75 \%)$ in all groups (Fig. $3 \mathrm{~b})$. T-bet can repress TNF, IL-2 and IL-17 ${ }^{16,17}$. Indeed, cKO CD8 ${ }^{+} \mathrm{T}$ cells produced more IL-2, TNF, and IL-17 on d8 p.i. (Supplementary Fig. 6). However, by d30 p.i., fewer T-bet cKO CD8 ${ }^{+} \mathrm{T}$ cells produced these cytokines upon restimulation compared to wild-type mice (Supplementary Fig. 6), suggesting that the reduction in virus-specific $\mathrm{CD}^{+} \mathrm{T}$ cells in cKO mice reflected loss of the cells rather than skewing towards an alternative lineage. Thus, T-bet appears to be required to sustain a virus-specific $\mathrm{CD} 8^{+} \mathrm{T}$ cell response during chronic viral infection. 


\section{T-bet expression inversely correlates with PD-1 expression}

PD-1 has a major role in regulating T cell exhaustion and repressing effective $\mathrm{T}$ cell responses during chronic infection ${ }^{2,3}$. PD-1 was highly upregulated on virus-specific $\mathrm{CD} 8^{+}$ $\mathrm{T}$ cells from clone 13 compared to Arm-infected mice (Fig. $4 \mathrm{a}-\mathrm{c}$ ). An inverse correlation between T-bet and PD-1 was evident after d8 p.i. during clone 13 infection (e.g. at day 26 p.i.; Fig. 4 b). PD- $1^{\text {Int }}$ exhausted CD $8^{+}$T cells were predominantly $T$-bet ${ }^{\text {Bright }}$, while nearly all the PD- ${ }^{\mathrm{Hi}}$ cells were $\mathrm{T}$-bet ${ }^{\mathrm{Dim}}$. In CD4-depleted, clone 13 infected mice, virus-specific $\mathrm{CD} 8^{+} \mathrm{T}$ cells were mostly PD- ${ }^{\mathrm{Hi}}$ and T-bet ${ }^{\mathrm{Dim}}$ (Fig. $4 \mathrm{~b}$ ). These results indicate that downregulation of T-bet is associated with higher PD-1 expression by exhausted CD8 ${ }^{+} \mathrm{T}$ cells.

At $\mathrm{d} 30$ p.i., virus-specific $\mathrm{CD}^{+} \mathrm{T}$ cells from cHet and the few remaining virus-specific $\mathrm{CD} 8^{+} \mathrm{T}$ cells in cKO mice were almost exclusively PD- $1^{\mathrm{Hi}}$ whereas wild-type cells contained both PD-1 ${ }^{\text {Int }}$ and PD- $1^{\mathrm{Hi}}$ subsets (Fig. 4c). T-bet deficiency also increased PD-1 expression in virus-specific CD4 T cells (Fig. 4c). These results suggest that T-bet can influence the expression of PD-1 and that this relationship between T-bet and PD-1 expression is not restricted to $\mathrm{CD} 8^{+} \mathrm{T}$ cells.

\section{Persisting antigen drives T-bet downregulation}

The loss of T-bet expression during chronic LCMV infection was somewhat paradoxical since inflammation can increase T-bet expression ${ }^{15}$. Based on previous in vitro work ${ }^{18}$ we tested whether persisting TCR stimulation during chronic infection might negatively impact T-bet expression. The V35A clone 13 variant, which contains a point mutation in the immunodominant $\mathrm{GP}_{33-41}$ epitope ${ }^{19}$ causes a chronic infection and, while lacking the $\mathrm{D}^{\mathrm{b}} \mathrm{GP} 33$ epitope, induces $\mathrm{T}$ cell responses to all other $\mathrm{CD} 8^{+} \mathrm{T}$ cell epitopes ${ }^{19}$. We infected mice with wild-type clone 13 and on $\mathrm{d} 8$ p.i. adoptively transferred $\mathrm{CD} 8^{+} \mathrm{T}$ cells from these mice into congenic mice infected 8 days previously with either wild-type or V35A clone 13 (Fig. 5 and Supplementary Fig. 7a). T-bet expression in $D^{\mathrm{b}} \mathrm{GP} 33$-specific $C D 8^{+} \mathrm{T}$ cells, which no longer received TCR stimulation, was significantly higher in V35A clone 13infected compared to wild-type clone 13-infected hosts (Fig. 5b). No significant changes in T-bet or PD-1 expression were observed in $\mathrm{D}^{\mathrm{b}} \mathrm{GP} 276$-specific $\mathrm{CD} 8^{+} \mathrm{T}$ cells, which were subjected to persisting TCR stimulation, in wild-type or V35A infected recipients (Fig 5b). T-bet was also higher in $\mathrm{D}^{\mathrm{b}} \mathrm{GP} 33$-specific $\mathrm{CD} 8^{+} \mathrm{T}$ cells compared to $\mathrm{D}^{\mathrm{b}} \mathrm{GP} 276$-specific $\mathrm{CD}^{+} \mathrm{T}$ cells in $\mathrm{V} 35 \mathrm{~A}$ infected recipients, while in mice infected with wild-type clone $13 \mathrm{~T}$ bet expression was similar in these two populations. Failure of the $\mathrm{D}^{\mathrm{b}} \mathrm{GP} 33$-specific $\mathrm{CD} 8^{+} \mathrm{T}$ cells to down-regulate T-bet in mice infected with the V35A variant virus indicates that persisting TCR stimulation was required for decreased T-bet expression during chronic LCMV infection.

\section{Cell-intrinsic T-bet regulation of PD-1 expression}

To determine whether T-bet had an intrinsic role in regulating PD-1, we used chimeric and adoptive transfer strategies where wild-type and T-bet deficient $\mathrm{T}$ cells were present in the same host and therefore subjected to the same viral load, inflammation or changes in other cell types such as $\mathrm{CD} 4^{+} \mathrm{T}$ cells or dendritic cells (Supplementary Fig. 7b-e). 
Polyclonal mixed peripheral chimeras were established by adoptive transfer of total CD8 ${ }^{+} \mathrm{T}$ cells from CD45.2+ $2^{+}$-bet $\mathrm{cKO}$ or cHet mice into $\mathrm{CD} 45.1^{+}$wild-type mice, followed by LCMV infection (Supplementary Fig. 7b, c and Fig. 6a, b). On d8 p.i., cKO virus-specific $\mathrm{CD}^{+} \mathrm{T}$ cells in clone 13 infected mice expressed significantly higher PD-1 than wild-type tetramer ${ }^{+} \mathrm{CD}^{+} \mathrm{T}$ cells in the same mice. A difference in PD-1 was also apparent after acute infection although to a more modest extent (Fig. 6a). Antigen-specific cKO CD8 ${ }^{+} \mathrm{T}$ cells were nearly undetectable in the chimeric mice at later time points (data not shown; consistent with Fig. 2). To examine inhibitory receptor expression over time, we generated cHet chimeras, because $\mathrm{cHet} C \mathrm{CD} 8^{+} \mathrm{T}$ cells persisted longer than $\mathrm{cKO} \mathrm{CD} 8^{+} \mathrm{T}$ cells during chronic LCMV infection. On $\sim \mathrm{d} 40$ p.i., cHet tetramer ${ }^{+} \mathrm{CD} 8^{+} \mathrm{T}$ cells were exclusively PD- $1^{\mathrm{Hi}}$, while the wild-type tetramer ${ }^{+} \mathrm{CD} 8^{+} \mathrm{T}$ cells in the same animals contained both PD-1 ${ }^{\mathrm{Hi}}$ and PD-1 ${ }^{\text {Int }}$ cells. These experiments suggest a cell-intrinsic role for T-bet in regulating PD-1 expression.

To address these questions in a setting where potential differences in precursor frequency or TCR repertoire were not a factor, equal numbers of wild-type and T-bet ${ }^{+/-} \mathrm{P} 14 \mathrm{CD} 8^{+} \mathrm{T}$ cells were co-transferred into wild-type mice (T-bet-deficient P14 failed to persist long term in clone 13 infected mice (data now shown)), followed by LCMV infection (Supplementary Fig. 7d). By d40 following clone 13 infection, nearly all T-bet ${ }^{+/-}$P14 were PD- ${ }^{\mathrm{Hi}}$, while the wild-type $\mathrm{P} 14$ population in the same hosts contained both $\mathrm{PD}-1^{\mathrm{Hi}}$ and $\mathrm{PD}-1^{\mathrm{Int}}$ cells (Fig. 6c). PD-1 expression was also slightly elevated in T-bet ${ }^{+/}$P14 cells compared to wildtype P14 cells even after Arm infection (Fig. 6c). Together, these experiments demonstrate a cell-intrinsic role for T-bet in regulating PD-1 expression in CD8 ${ }^{+} \mathrm{T}$ cells. The impact of Tbet on PD-1 expression was modest during acute infection but it became more dramatic during chronic infection.

\section{Overexpressed T-bet Sustains CD8+ Responses in Chronic Infection}

During acute infection, T-bet promotes the formation of short-lived, terminally differentiated $\mathrm{CD} 8^{+} \mathrm{T}$ cells ${ }^{15}$. To test the impact of higher $\mathrm{T}$-bet expression on $\mathrm{CD} 8^{+} \mathrm{T}$ cell responses during chronic infection, we retrovirally overexpressed T-bet in $\mathrm{P} 14 \mathrm{CD} 8^{+} \mathrm{T}$ cells (Supplementary Fig. 7e). T-bet-transduced P14 cells (marked by GFP expression (Fig. 7a)) were adoptively transferred into mice infected with either Arm or clone 13. During Arm infection, the percentage of terminally differentiated IL-7 $\mathrm{R}^{\mathrm{Lo}} \mathrm{CD} 8^{+} \mathrm{T}$ cells was increased among $\mathrm{GFP}^{+} \mathrm{P} 14$ cells transduced with T-bet $\mathrm{RV}$ compared to non-transduced $\left(\mathrm{GFP}^{-}\right)$cells in the same host or P14 cells transduced with empty RV (Fig. 7b). Consequently, GFP ${ }^{+}, \mathrm{T}-$ bet-transduced P14 cells did not persist as well as the $\mathrm{GFP}^{+} \mathrm{P} 14$ cells transduced with the empty vector (Fig. 7c), in agreement with previous work ${ }^{15}$.

During chronic infection, T-bet over-expression skewed $\mathrm{GFP}^{+} \mathrm{P} 14$ cells towards the PD- $1^{\text {Int }}$ subset (Fig. 7b). Compared to the empty-vector control, T-bet overexpression also enhanced persistence of $\mathrm{P} 14$ cells during chronic infection and a higher percentage of $\mathrm{GFP}^{+} \mathrm{T}$-betoverexpressing compared to $\mathrm{GFP}^{-}$cells was present, especially at later time points (>day 20 p.i.) (Fig. 7c). These results suggest that increasing T-bet expression reduced PD-1 and improved the persistence of exhausted $\mathrm{CD} 8^{+} \mathrm{T}$ cells during chronic infection. 


\section{T-bet represses a set of inhibitory receptors}

Exhausted $\mathrm{CD}^{+} \mathrm{T}$ cells upregulate a number of inhibitory receptors, which act synergistically with PD-1 to promote exhaustion $4,8,11$. To test whether T-bet might also impact expression of other inhibitory receptors we next examined the expression of Lag-3, BTLA, CD160, KLRG-1, CD244, and Tim-3 on virus-specific CD8 ${ }^{+}$T cells from wild-type and cHet mice at $\mathrm{d} 40$ following clone 13 infection (Fig. 8a). In cHet mice, exhausted tetramer ${ }^{+} \mathrm{CD} 8^{+} \mathrm{T}$ cells were predominantly Lag- $3^{\mathrm{Hi}}, \mathrm{CD} 160^{\mathrm{Hi}}$, and $\mathrm{BTLA}{ }^{\mathrm{Hi}}$, suggesting that T-bet coordinately repressed these receptors during chronic LCMV infection. In contrast, KLRG-1 expression was reduced in cHet mice, consistent with previous studies demonstrating a positive role of T-bet in KLRG1 expression during acute infections ${ }^{15}$. The effect of T-bet on CD244 and Tim-3 expression was more complex, since PD- ${ }^{\mathrm{Hi}}$ cells in cHet mice showed heterogenous expression of these receptors. In addition, we observed changes in expression of a number of markers in T-bet-deficient antigen-specific $\mathrm{CD} 8^{+} \mathrm{T}$ cells during chronic infection (Supplementary Fig. 8).

Using the wild-type plus T-bet ${ }^{+/-}$P14 co-transfers strategy described above we also found that Lag-3, CD160, and BTLA expression was increased on T-bet ${ }^{+/-}$P14 cells (Fig. 8b). There was a slight shift towards increased CD244 expression, while Tim-3 expression was unchanged or slightly lower in T-bet ${ }^{+/-}$P14 cells. T-bet appeared to have a role in the early expression of Tim-3 since T-bet ${ }^{-/-}$P14 cells expressed less Tim-3 compared to wild-type P14 at d9 p.i. in during Arm or clone 13 infection, (Supplementary Fig. 9), consistent with a role for T-bet in the initial expression of Tim- $3^{20}$.

Increased T-bet expression using the retroviral overexpression approach in P14 cells increased KLRG-1 expression (Fig. 8c), but repressed Lag-3, CD160, and BTLA along with PD-1 during chronic LCMV infection. These results support a cell-intrinsic role for T-bet in regulating multiple inhibitory receptors and likely other genes in exhausted $\mathrm{CD} 8^{+} \mathrm{T}$ cells.

\section{T-bet is a direct transcriptional repressor of PD-1}

To address whether T-bet repressed $P d c d l$ transcription directly we used EL4 cells that constitutively express PD- ${ }^{21}$ but minimal amounts of T-bet (Fig. 9a, b) ${ }^{22}$. Ectopic expression of T-bet in EL4 cells significantly downregulated PD-1 (Fig. 9b,c). To identify the regulatory elements of the $P d c d l$ locus targeted by T-bet, we used a luciferase reporter construct containing two highly conserved regulatory regions (CR-B and CR-C) found in a $\sim 2300 \mathrm{bp}$ fragment upstream of $P d c d 1$. CR-C was reported to contain an NFAT site important for the transcriptional induction of $P d c d l$ upon activation ${ }^{21}$, while the role of CR$B$ remains unknown. Significant transcriptional activity was observed upon PMA and ionomycin activation with the full length construct (PD-1 B+C) but not with a version containing only the CR-B region (PD-1 B; Fig. 9d and Supplementary Fig. 10a), as previously reported ${ }^{21}$. T-bet inhibited the activity of the PD-1 B+C reporter by $\sim 60-70 \%$ (Fig. 9d). A version of T-bet containing point mutations that abrogate DNA binding (T-bet D.B.M. $)^{23}$ was expressed at similar levels to wild-type T-bet, but was unable to mediate repression of the reporter (Fig. 9d and Supplementary Fig. 10). Thus, T-bet repressed PD-1 expression in a manner that required DNA binding. 
Consistent with the EL4 data, P14 cells retrovirally transduced with T-bet expressed less PD-1 than cells transduced with the empty vector after 3 days of culture (Fig. 9e,f), although the extent of PD-1 repression was less dramatic than observations made in vivo during chronic infection (Fig. 7b). Thus, genetic ablation in vivo as well as over-expression in vitro and in vivo all demonstrate repression of PD-1 expression by T-bet.

To test whether T-bet bound directly to regulatory elements of $P d c d l$, we performed chromatin immunoprecipation (ChIP). Specific enrichment of T-bet at the $P d c d l$ region was not detected following ChIP in exhausted $\mathrm{CD} 8^{+} \mathrm{T}$ cells isolated from clone 13-infected mice (Fig. 9g), though some binding to the Ifng locus was observed in these cells, likely due to a more optimal T-bet binding site in the regulatory region of this gene. In contrast, in CD8 ${ }^{+} \mathrm{T}$ cells activated in vitro or isolated from Arm immune mice, both cells that expressed less PD-1 than exhausted CD8 ${ }^{+}$T cells, T-bet physically associated with $P d c d l$ within a region $\sim 500 \mathrm{bp}$ upstream of the transcriptional start site, near or within the "B" region (Fig. 9g). Binding to the $P d c d 1$ regulatory region was not detected in $T b x 21^{--} \mathrm{CD} 8^{+} \mathrm{T}$ cells (Supplementary Fig. 11). T-bet binding to $P d c d l$ was, however, also observed in in vitro activated, $\mathrm{T}_{\mathrm{H}} 1$ polarized $\mathrm{CD} 4^{+} \mathrm{T}$ cells (Fig. $9 \mathrm{~h}$ ). Together, these results demonstrate that $\mathrm{T}$ bet acts as a repressor of PD-1 expression via direct binding to upstream regulatory elements of $P d c d 1$.

\section{Discussion}

In this study, we demonstrate a critical role of $\mathrm{T}$-bet in sustaining antiviral CD8 $8^{+} \mathrm{T}$ cell responses during chronic viral infection. In contrast to acute infection, high T-bet expression improved the long-term durability of antigen-specific $\mathrm{CD} 8^{+} \mathrm{T}$ cells during chronic infection. Sustained T-bet expression repressed inhibitory receptors, while low T-bet resulted in high expression of PD-1 and exacerbated CD8 ${ }^{+} \mathrm{T}$ cell exhaustion.

T-bet directly repressed PD-1 expression in LCMV-specific CD4 ${ }^{+}$and CD8 ${ }^{+} \mathrm{T}$ cells and bound to the regulatory region upstream of $P d c d l$. A previously identified NFAT site critical for PD-1 expression ${ }^{21}$ is also located upstream of $P d c d 1$ suggesting potential transcription factor cooperation or antagonism in PD-1 expression. Indeed, T-bet can repress NFAT-mediated transactivation in other settings ${ }^{29}$, but the connection between T-bet and NFAT on $P d c d l$ transcription will require further analysis. In addition to a possible relationship between NFAT and T-bet, Blimp-1 and T-bet have analogous roles during acute infection where high expression of these two transcription factors drives $\mathrm{CD} 8^{+} \mathrm{T}$ cells to become functional, terminally differentiated effectors ${ }^{14,15}$. However, these two transcription factors seem to have opposing roles during chronic infection, where high Blimp- $1^{12}$ promotes exhaustion and inhibitory receptor expression while T-bet is low in this setting. A tightly coupled reciprocal expression pattern is also observed between T-bet and Eomesodermin ${ }^{16,17}$ and between Blimp- 1 and $\mathrm{Bcl}^{30}{ }^{30}$, suggesting a complex but coordinated transcriptional program. In addition, since T-bet (and Blimp- $1^{12}$ ) also regulated expression of LAG-3, BTLA and CD160, it will be important to further define how the constellation of key transcription factors expressed by exhausted $\mathrm{T}$ cells cooperates to guide this developmental program. 
$P d c d l$ was not identified as a target for T-bet using either ChIP-Chip ${ }^{31}$ or ChIP-Seq (unpublished observations). The binding of T-bet to $P d c d l$ appears to be weaker than for other canonical targets like Ifng, and typical dimeric T-bet sites were not identified in the $P d c d l$ region where T-bet binds, suggesting that T-bet might interact with degenerate T-box half sites found in this region. It is possible that this T-bet- $P d c d l$ interaction falls below the limit of detection of these genome-wide techniques. Such a model could also explain why in exhausted $\mathrm{CD} 8^{+} \mathrm{T}$ cells where T-bet expression is low, binding of T-bet to $P d c d l$ is lost, but binding to more optimal sites like Ifng is preserved. In other settings such as memory or in vitro activated $\mathrm{CD} 8^{+} \mathrm{T}$ cells where $\mathrm{T}$-bet levels are higher, there is likely sufficient $\mathrm{T}$-bet protein to bind to weaker sites such as in $P d c d l$. Thus, while large-scale screening approaches are invaluable, alternative methods might be required to identify other potentially important biological transcriptional targets.

The relationship between T-bet and PD-1 may differ depending on the context. For example, the inverse correlation between PD-1 and T-bet during chronic infection becomes apparent only after $\sim$ d 15 p.i. In addition, genetic ablation of T-bet during acute infection slightly increased PD-1 expression on $\mathrm{CD} 8^{+} \mathrm{T}$ cells, but on its own was insufficient to drive PD-1 expression to the extent observed during chronic infection. Therefore, persisting antigen signals or other transcription factors together with T-bet likely provide context-specific and temporal regulation of PD-1 and other inhibitory receptors. Importantly, virus-specific CD8 ${ }^{+}$ $\mathrm{T}$ cells in chronically infected cKO and cHet mice express comparably high PD-1, but the defects in $\mathrm{cKO} \mathrm{CD} 8^{+} \mathrm{T}$ cells are much more pronounced, suggesting a PD-1-independent role for residual T-bet in cHet mice. Nevertheless, T-bet is a critical transcriptional regulator of $P d c d l$ and affects the expression of multiple inhibitory receptors, especially during later stages of chronic infection.

The distinct expression of T-bet during acute and chronic viral infection also has potential implications for understanding the molecular relationship between terminal differentiation and exhaustion. High T-bet expression promotes terminal differentiation ${ }^{15,} 16$ but represses certain features of exhaustion. Notably, phenotypic markers of terminal differentiation such KLRG- $1^{4,8}$, or CD57 are not necessarily correlated with exhaustion or PD-1

expression $^{32,33}$. These observations, including the distinct roles of T-bet during acute versus chronic infection, support the notion that terminal differentiation and exhaustion of $\mathrm{CD} 8^{+} \mathrm{T}$ cells follow distinct molecular paths, although further studies are clearly warranted.

Low T-bet expression during chronic compared to acute LCMV infection was unexpected, given the elevated antigen and inflammation associated with clone 13 infection. Increases in IFN- $\alpha$, IFN- $\beta^{24}$ and IFN- $\gamma^{25}$ and of IFN responsive genes ${ }^{4}$ are observed during chronic LCMV infection. IFN- $\gamma$ signaling reinforces T-bet expression during $\mathrm{T}_{\mathrm{H}} 1$ differentiation ${ }^{26}$, and type I IFN can induce IFN- $\gamma$ production ${ }^{27}$ or might itself regulate T-bet ${ }^{28}$. While TCR signaling is necessary for initiating T-bet induction, we found that prolonged TCR stimulation led to T-bet downregulation in the presence of persisting inflammation. One possible mechanism based on in vitro data and modeling work ${ }^{18}$ as well as the in vivo studies presented here is that persisting TCR signaling decouples the ability of inflammation to increase or sustain T-bet expression. These observations suggest that there might be 
opportunities to preserve T-bet expression during chronic infection if the intracellular regulatory mechanisms can be defined.

In humans, chronic infections can also lead to $\mathrm{T}$ cell exhaustion and upregulation of inhibitory receptors, such as PD- $1^{2}$. Given the potential relationship between antigen, inflammation, and T-bet it will be interesting to investigate T-bet and PD-1 co-expression in some of these settings. During chronic HCV infection, pegylated type I IFN therapy is effective in only a subset of patients and examining whether T-bet correlates with clinical outcome of HCV infection and/or IFN treatment could be informative. While the expression of T-bet in T cells responding to latent and/or reactivating viral infections could be different, for infections with sustained and high viral replication our data indicates that dysregulation of T-bet expression could underlie at least part of the defects in exhausted CD8 ${ }^{+} \mathrm{T}$ cells including high expression of inhibitory receptors and failure to sufficiently sustain $\mathrm{T}$ cell immunity. Future studies that aim to increase T-bet expression might have therapeutic benefits during chronic viral infections in humans.

\section{Methods}

\section{Mice strains}

C57BL/6 (B6) and congenic (CD45.1) B6 mice were purchased from NCI. Tbx $21^{\mathrm{fl}}$ mice were used previously ${ }^{17}$; these mice were backcrossed to $\mathrm{B} 6$ for at least 10 generations, then crossed with CD4-Cre transgenic mice to produce F1 littermates that were intercrossed to generate mice with conditional deletion of T-bet at one (cHet) or both alleles (cKO). Germline T-bet knockouts $\left(\mathrm{Tb} \times 21^{-/-}\right)^{34}$ were crossed with P14 TCR transgenics on a CD45.1 background; the littermates were intercrossed to produce P14 TCR transgenics on a mixed CD45.1/CD45.2 background with deletion of one or both alleles of T-bet. Mice were used between 5-20 weeks of age. All mice were age-matched in experiments comparing B6 mice with T-bet cHet and cKO mice. All animal work was performed in accordance with the Institute Animal Care and Use Guidelines for the University of Pennsylvania, University of Washington, and the Wistar Institute.

\section{Viral infections, plaque assays, and in vivo antibody treatments}

LCMV strains were produced and titered ${ }^{35}$ as described. Mice were infected with LCMV Armstrong $\left(2 \times 10^{5} \mathrm{PFU}\right)$ by intraperitoneal (i.p.) injection or LCMV clone $13\left(4 \times 10^{6} \mathrm{PFU}\right.$ for wild type and $2 \times 10^{6} \mathrm{PFU}$ from V35A variant) intravenously (i.v.). The V35A variant strain of clone 13 was described previously ${ }^{19}$. For infections in CD4 depleted mice, $200 \mu \mathrm{g}$ of anti-CD4 antibody (GK1.5; BioXcell) was injected twice i.p., one day before and one day after clone 13 infection.

\section{Flow cytometry, antibodies, reagents, and peptide restimulations}

Lymphocytes were isolated from blood, bone marrow, spleen, lymph node, brain, and liver as described ${ }^{36}$. Biotinylated $\mathrm{H}-2 \mathrm{D}^{\mathrm{b}}(\mathrm{gp} 33)$ or $\mathrm{H}-2 \mathrm{D}^{\mathrm{b}}(\mathrm{gp} 276)$ monomers were produced, refolded, biotinylated, and tetramerized with streptavidin-APC (Molecular Probes/ Invitrogen) as described ${ }^{36}$. I- $\mathrm{A}^{\mathrm{b}} \mathrm{GP}_{66-77}$ tetramers were obtained from the NIH Tetramer Core (Atlanta, GA). Antibodies for flow cytometry are outlined in Supplementary Table 1. 
Surface staining with antibodies and tetramers for flow cytometry was described ${ }^{36}$, and intracellular cytokine staining was performed using the Cytofix/Cytoperm kit according to the manufacturer's instructions (BD Biosciences). Intracellular staining using T-bet antibody (4B10; Santa Cruz Biotechnology) conjugated to FITC or AlexaFluor488 was performed by fixation of cells in $1 \%$ formaldehyde in PBS, followed by permeabilization and staining for 1-2 hours in $0.1 \%$ Triton X-100 and 1\% FBS in PBS, then fixation again in 1\% formaldehyde in PBS. Lymphocytes were restimulated with individual LCMV peptides $(\sim 200 \mathrm{nM})$ or a pool of $20 \mathrm{LCMV}$ peptides ${ }^{37}$ for $5-7 \mathrm{~h}$ at $37^{\circ} \mathrm{C}$ in $5 \% \mathrm{CO}_{2}$ incubator. Flow cytometry was performed using an LSR II (BD ImmunoCytometry Systems), and the data was analyzed with FlowJo 9.0.1 (Treestar).

\section{Cell lines}

The 293T cell line was provided by W. Pear (University of Pennsylvania). EL4 and A20 cell lines were obtained from ATCC.

\section{Retroviral production, transduction, CFSE labeling, and adoptive transfer}

T-bet cDNA was previously cloned into the MIG retrovirus ${ }^{38}$. Empty MIG or T-bet-MIG was retrovirus was produced in $293 \mathrm{~T}$ cells using the calcium phosphate method as described ${ }^{39}$. Naive $\mathrm{P} 14$ cells were activated with $\mathrm{GP}_{33-41}$ peptide in vitro for $12-24 \mathrm{~h}$, then transduced with retroviral supernatants by "spin-fection": $1 \mathrm{~mL}$ of retroviral supernatant containing $0.8 \mu \mathrm{g} / \mathrm{mL}$ polybrene mixed with $\sim 1 \times 10^{6}$ activated P14 cells in 24-well plates and centrifuged $90 \mathrm{~min}, 1200 \times \mathrm{g}, 20^{\circ} \mathrm{C}$. P14 cells (5000 CD8+) were then immediately transferred i.v. into B6 hosts (infected 12-24 h previously with LCMV Arm or clone 13). Transduction was performed in EL4 without preactivation. For experiments assessing early T-bet expression in antigen-specific $\mathrm{CD} 8^{+} \mathrm{T}$ cells, $\mathrm{P} 14 \mathrm{CD} 8^{+}$splenocytes were labeled with CFSE as previously described ${ }^{36}$, and $1 \times 10^{6}$ labeled P14 CD8+ cells were transferred i.v. into congenic B6 hosts, infected with Arm or clone 13 the next day, then sacrificed on d1 or d3 p.i. to examine donor P14 in the spleen. For mixed P14 T-bet chimeras, equal numbers (1000) of WT and $T b x 21^{+/-}$or $T b x 21^{-/-} \mathrm{CD}^{+} \mathrm{P} 14$ splenocytes were co-transferred (i.v.) into congenic B6 hosts, then infected with Arm or clone 13 and analyzed on the days indicated. For adoptive transfer experiments of $T b x 2 I^{\mathrm{fl}} \mathrm{CD} 4-\mathrm{Cre}$ cells into B6 hosts, suspension of splenocytes containing $2 \times 10^{7} \mathrm{CD}^{+} \mathrm{T}$ cells were transferred i.v. into each congenic B6 host, then infected with Arm or clone 13. For transfer experiments involving V35A variant clone 13 infection, donor mice were initially infected with WT clone 13; at d8 p.i. splenocytes from donor mice were enriched for $\mathrm{CD}^{+} \mathrm{T}$ cells by negative selection using DynaBeads (Invitrogen), then $\sim 1.5 \times 10^{6} \mathrm{gp} 33$-specific CD8 ${ }^{+}$cells (and $~ 1.0 \times 10^{6} \mathrm{GP} 276$ specific CD8 T cells) were transferred i.v. into congenic hosts infected 8 days ago with WT clone 13 or V35A variant.

\section{$\mathrm{CD4}^{+}$and $\mathrm{CD}^{+} \mathrm{T}$ cell stimulations, chromatin immunoprecipitation, PCR}

Chromatin immunoprecipitation (ChIP) of in vitro activated, $\mathrm{T}_{\mathrm{H}} 1$ polarized WT or Tb $\times 21^{-1-}$ $\mathrm{CD}^{+} \mathrm{T}$ cells was performed as described ${ }^{22}$. WT or $\mathrm{Tb} \times 21^{-/-} \mathrm{P} 14$ splenocytes were stimulated with $50 \mathrm{nM}$ of GP $33-41$ peptide and cultured in $100 \mathrm{U} / \mathrm{mL}$ of IL-2 (NIH) for 5-6 days. The culture was split every 2 days using media containing IL-2. P14 cells were 
restimulated with PMA $(50 \mathrm{ng} / \mathrm{mL})$ and ionomycin $(1 \mu \mathrm{M})$ for $5 \mathrm{~h}$ before ChIP. For P14 cells, sonication of fixed cells was performed using a Bioruptor (Diagenode), and ChIP was performed using the ChIP assay kit according to the manufacturer's instructions (Millipore/ Upstate). Rabbit polyclonal anti-T-bet (H-210, Santa Cruz Biotechnology) or normal rabbit IgG was used for ChIP. Primers for amplifying the region upstream of $P d c d l$ were: $-0.5 \mathrm{~kb}$ region (forward) 5'-GGTGTCTGGAGAGGAAAGGC-3' and (reverse) $5^{\prime}$ -

CTACCTTGTCTGCCATGCGTG' $3^{\prime} ;-1.5 \mathrm{~kb}$ region (forward) $5^{\prime}$ -

CCTTGCTCCTCACCACACTGC-3' and (reverse) $5^{\prime}$ -

CAGAGCAGATCATGAGGACTG-3'. ChIP primers for Ifng and Hprtl were described previously ${ }^{40}$

\section{DNA constructs, EL4 restimulation, and luciferase assay}

Construction of the PD-1 reporter containing either $\sim 400 \mathrm{bp}$ (PD-1 B) or $\sim 2300 \mathrm{bp}$ (PD-1 B

$+\mathrm{C}$ ) of $P d c d l$ upstream regulatory elements into the pGL3Basic vector (Promega) and pEF1 (Invitrogen) with T-bet were previously described ${ }^{21,29}$. T-bet DNA-binding mutant (DBM) contains double point mutations of arginies 163 and 164 as described previously ${ }^{23}$.

Restimulation of EL4 cells with PMA and ionomycin and transfection using the Nucleofection kit (Amaxa/Lonza) was performed as described ${ }^{22}$. The dual luciferase assay was performed according to the manufacture's instructions (Promega) and normalized to the expression of the renilla luciferase control vector, pRL (Promega).

\section{Statistical analysis}

$\mathrm{P}$ value for statistical significance was determined using paired or unpaired two-tailed Student's $t$-test.

\section{Supplementary Material}

Refer to Web version on PubMed Central for supplementary material.

\section{Acknowledgments}

We thank members of the Wherry and Reiner labs as well as M.R. Betts (University of Pennsylvania) for helpful comments and insights, N. Cereb and S. Y. Yang from Histogenetics, Inc. (Hawthorne, NY) and L. Boring from Xenogen Biosciences (Cranbury, NJ) for assistance with construction of the floxed T-bet allele. This work was supported by an NIH training grant (AI007518 to CK) and grants from the NIH/NIAD (AI071309, AI082630, AI083022, HHSN266200500030C to EJW; AI061699, AI076458 to SLR), the Foundation for NIH and Grand Challenge in Global Health (to EJW), and the Dana Foundation (to EJW).

\section{References}

1. Williams MA, Bevan MJ. Effector and memory CTL differentiation. Annu Rev Immunol. 2007; 25:171-192. [PubMed: 17129182]

2. Virgin HW, Wherry EJ, Ahmed R. Redefining chronic viral infection. Cell. 2009; 138:30-50. [PubMed: 19596234]

3. Barber DL, et al. Restoring function in exhausted CD8 T cells during chronic viral infection. Nature. 2006; 439:682-687. [PubMed: 16382236]

4. Wherry EJ, et al. Molecular signature of CD8+ T cell exhaustion during chronic viral infection. Immunity. 2007; 27:670-684. [PubMed: 17950003] 
5. Fourcade J, et al. Upregulation of Tim-3 and PD-1 expression is associated with tumor antigenspecific CD8+ T cell dysfunction in melanoma patients. J Exp Med.

6. Sakuishi K, et al. Targeting Tim-3 and PD-1 pathways to reverse T cell exhaustion and restore antitumor immunity. J Exp Med.

7. Brahmer JR, et al. Phase I study of single-agent anti-programmed death-1 (MDX-1106) in refractory solid tumors: safety, clinical activity, pharmacodynamics, and immunologic correlates. J Clin Oncol. 28:3167-3175. [PubMed: 20516446]

8. Blackburn SD, et al. Coregulation of CD8+ T cell exhaustion by multiple inhibitory receptors during chronic viral infection. Nat Immunol. 2009; 10:29-37. [PubMed: 19043418]

9. Jones RB, et al. Tim-3 expression defines a novel population of dysfunctional T cells with highly elevated frequencies in progressive HIV-1 infection. J Exp Med. 2008; 205:2763-2779. [PubMed: 19001139]

10. Jin HT, et al. Cooperation of Tim-3 and PD-1 in CD8 T-cell exhaustion during chronic viral infection. Proc Natl Acad Sci U S A. 107:14733-14738. [PubMed: 20679213]

11. Vali B, et al. HCV-specific T cells in HCV/HIV co-infection show elevated frequencies of dual Tim-3/PD-1 expression that correlate with liver disease progression. Eur J Immunol. 40:24932505. [PubMed: 20623550]

12. Shin $\mathrm{H}$, et al. A role for the transcriptional repressor Blimp-1 in CD8(+) T cell exhaustion during chronic viral infection. Immunity. 2009; 31:309-320. [PubMed: 19664943]

13. Kallies A, Xin A, Belz GT, Nutt SL. Blimp-1 transcription factor is required for the differentiation of effector CD8(+) T cells and memory responses. Immunity. 2009; 31:283-295. [PubMed: 19664942]

14. Rutishauser RL, et al. Transcriptional repressor Blimp-1 promotes CD8(+) T cell terminal differentiation and represses the acquisition of central memory T cell properties. Immunity. 2009; 31:296-308. [PubMed: 19664941]

15. Joshi NS, et al. Inflammation directs memory precursor and short-lived effector CD8(+) T cell fates via the graded expression of T-bet transcription factor. Immunity. 2007; 27:281-295. [PubMed: 17723218]

16. Intlekofer AM, et al. Requirement for T-bet in the aberrant differentiation of unhelped memory CD8+ T cells. J Exp Med. 2007; 204:2015-2021. [PubMed: 17698591]

17. Intlekofer AM, et al. Anomalous type 17 response to viral infection by CD8+ T cells lacking T-bet and eomesodermin. Science. 2008; 321:408-411. [PubMed: 18635804]

18. Schulz EG, Mariani L, Radbruch A, Hofer T. Sequential polarization and imprinting of type $1 \mathrm{~T}$ helper lymphocytes by interferon-gamma and interleukin-12. Immunity. 2009; 30:673-683. [PubMed: 19409816]

19. Shin H, Blackburn SD, Blattman JN, Wherry EJ. Viral antigen and extensive division maintain virus-specific CD8 T cells during chronic infection. J Exp Med. 2007; 204:941-949. [PubMed: 17420267]

20. Anderson AC, et al. T-bet, a Th1 transcription factor regulates the expression of Tim-3. Eur J Immunol. 40:859-866. [PubMed: 20049876]

21. Oestreich KJ, Yoon H, Ahmed R, Boss JM. NFATc1 regulates PD-1 expression upon T cell activation. J Immunol. 2008; 181:4832-4839. [PubMed: 18802087]

22. Beima KM, et al. T-bet binding to newly identified target gene promoters is cell type-independent but results in variable context-dependent functional effects. J Biol Chem. 2006; 281:11992-12000. [PubMed: 16473879]

23. Miller SA, Huang AC, Miazgowicz MM, Brassil MM, Weinmann AS. Coordinated but physically separable interaction with H3K27-demethylase and H3K4-methyltransferase activities are required for T-box protein-mediated activation of developmental gene expression. Genes Dev. 2008; 22:2980-2993. [PubMed: 18981476]

24. Louten J, van Rooijen N, Biron CA. Type 1 IFN deficiency in the absence of normal splenic architecture during lymphocytic choriomeningitis virus infection. J Immunol. 2006; 177:32663272. [PubMed: 16920967]

25. Mackerness KJ, et al. Pronounced virus-dependent activation drives exhaustion but sustains IFNgamma transcript levels. J Immunol. 185:3643-3651. [PubMed: 20720198] 
26. Afkarian M, et al. T-bet is a STAT1-induced regulator of IL-12R expression in naive CD4+ T cells. Nat Immunol. 2002; 3:549-557. [PubMed: 12006974]

27. Nguyen KB, et al. Critical role for STAT4 activation by type 1 interferons in the interferon-gamma response to viral infection. Science. 2002; 297:2063-2066. [PubMed: 12242445]

28. Hibbert L, Pflanz S, De Waal Malefyt R, Kastelein RA. IL-27 and IFN-alpha signal via Stat1 and Stat 3 and induce T-Bet and IL-12Rbeta2 in naive T cells. J Interferon Cytokine Res. 2003; 23:513-522. [PubMed: 14565860]

29. Mehta DS, Wurster AL, Weinmann AS, Grusby MJ. NFATc2 and T-bet contribute to T-helpercell-subset-specific regulation of IL-21 expression. Proc Natl Acad Sci U S A. 2005; 102:20162021. [PubMed: 15684054]

30. Crotty S, Johnston RJ, Schoenberger SP. Effectors and memories: Bcl-6 and Blimp-1 in T and B lymphocyte differentiation. Nat Immunol. 11:114-120. [PubMed: 20084069]

31. Jenner RG, et al. The transcription factors T-bet and GATA-3 control alternative pathways of Tcell differentiation through a shared set of target genes. Proc Natl Acad Sci U S A. 2009; 106:17876-17881. [PubMed: 19805038]

32. Petrovas C, et al. Differential association of programmed death-1 and CD57 with ex vivo survival of CD8+ T cells in HIV infection. J Immunol. 2009; 183:1120-1132. [PubMed: 19564339]

33. Day CL, et al. PD-1 expression on HIV-specific T cells is associated with T-cell exhaustion and disease progression. Nature. 2006; 443:350-354. [PubMed: 16921384]

34. Intlekofer AM, et al. Effector and memory CD8+ T cell fate coupled by T-bet and eomesodermin. Nat Immunol. 2005; 6:1236-1244. [PubMed: 16273099]

35. Ahmed R, Salmi A, Butler LD, Chiller JM, Oldstone MB. Selection of genetic variants of lymphocytic choriomeningitis virus in spleens of persistently infected mice. Role in suppression of cytotoxic T lymphocyte response and viral persistence. J Exp Med. 1984; 160:521-540. [PubMed: 6332167]

36. Wherry EJ, Blattman JN, Murali-Krishna K, van der Most R, Ahmed R. Viral persistence alters CD8 T-cell immunodominance and tissue distribution and results in distinct stages of functional impairment. J Virol. 2003; 77:4911-4927. [PubMed: 12663797]

37. Kotturi MF, et al. The CD8+ T-cell response to lymphocytic choriomeningitis virus involves the $\mathrm{L}$ antigen: uncovering new tricks for an old virus. J Virol. 2007; 81:4928-4940. [PubMed: 17329346]

38. Mullen AC, et al. Role of T-bet in commitment of TH1 cells before IL-12-dependent selection. Science. 2001; 292:1907-1910. [PubMed: 11397944]

39. Pear WS, Nolan GP, Scott ML, Baltimore D. Production of high-titer helper-free retroviruses by transient transfection. Proc Natl Acad Sci U S A. 1993; 90:8392-8396. [PubMed: 7690960]

40. Cruz-Guilloty F, et al. Runx3 and T-box proteins cooperate to establish the transcriptional program of effector CTLs. J Exp Med. 2009; 206:51-59. [PubMed: 19139168] 
a
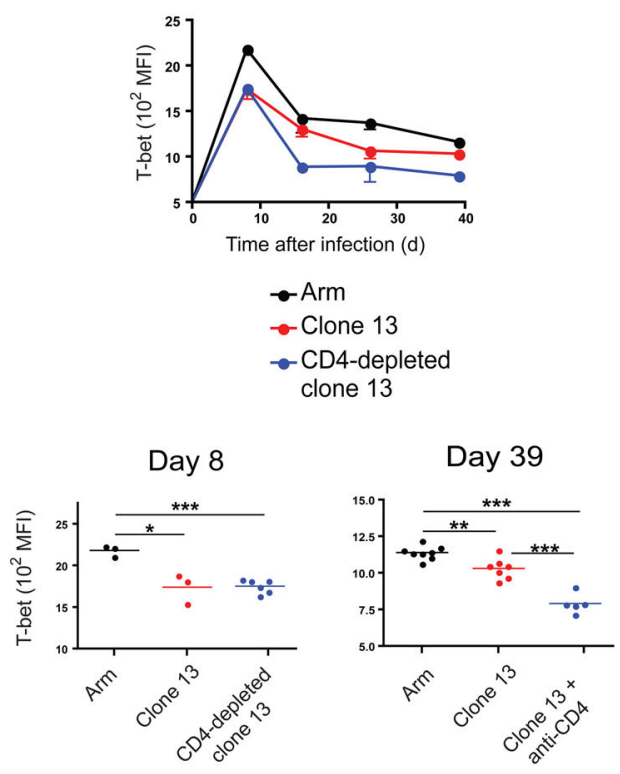

b

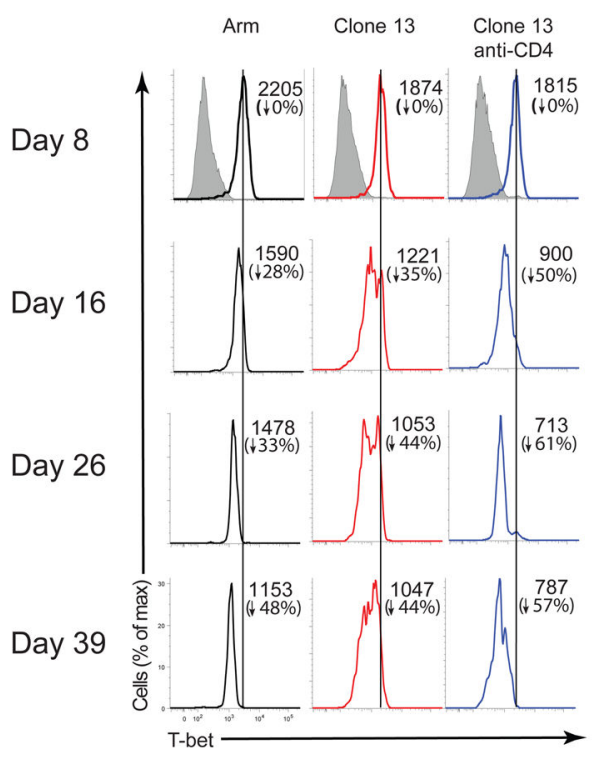

Figure 1. T-bet is downregulated during chronic compared to acute LCMV infection

(a) Mean fluorescence intensity (MFI) of intracellular T-bet in CD8 ${ }^{+}$gp33-specific T cells from C57BL/6 (B6) mice or CD4-depleted B6 mice infected with LCMV Arm or clone 13 and analyzed on the indicated days p.i.; top graph shows average MFI of each group for all time points measured, while bottom two graphs show MFI for individual animals at days 8 (left) and 39 (right) p.i. Statistical analysis: $* P<0.05$ or $* * * P<0.001$ (two-tailed unpaired Student's $t$-test; error bars, s.e.m.) (b) Histograms from representative animals at each time point p.i. from each group; numbers indicate MFI (top) and percent reduction in MFI with respect to day 8 p.i. (bottom); grey-shaded histograms on $\mathrm{d} 8$ are from $\mathrm{CD} 44^{\mathrm{Lo}} \mathrm{CD} 8^{+}$cells. Data are representative of at least three independent experiments with at least 3 mice per group. 
a

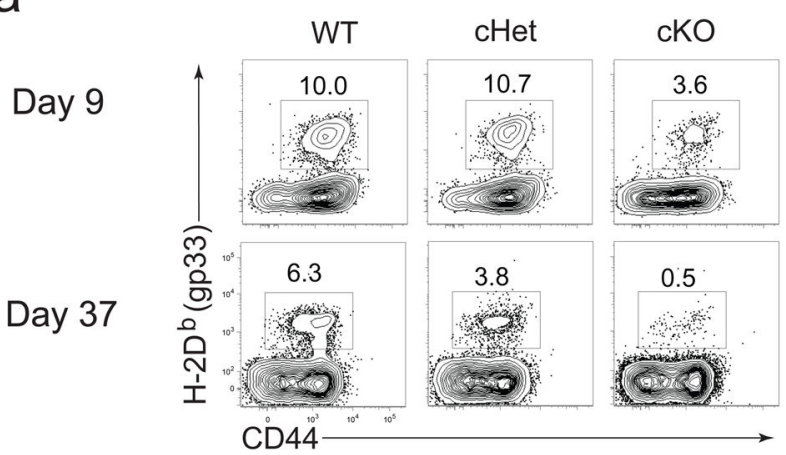

b

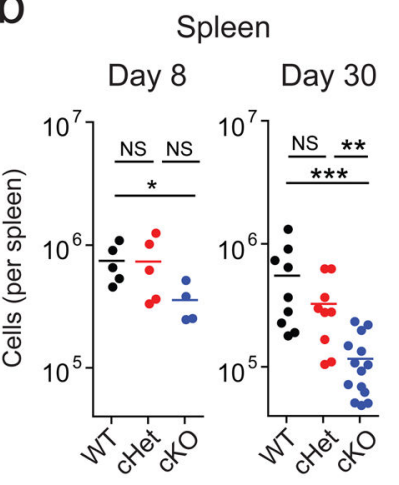

d Serum

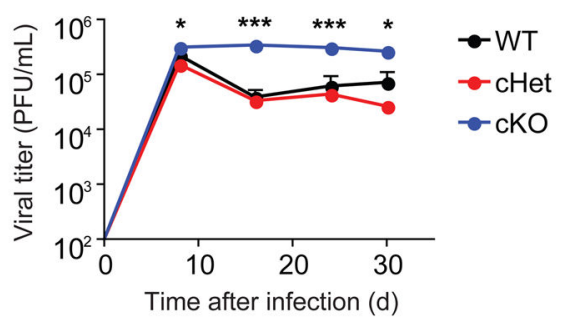

e
C

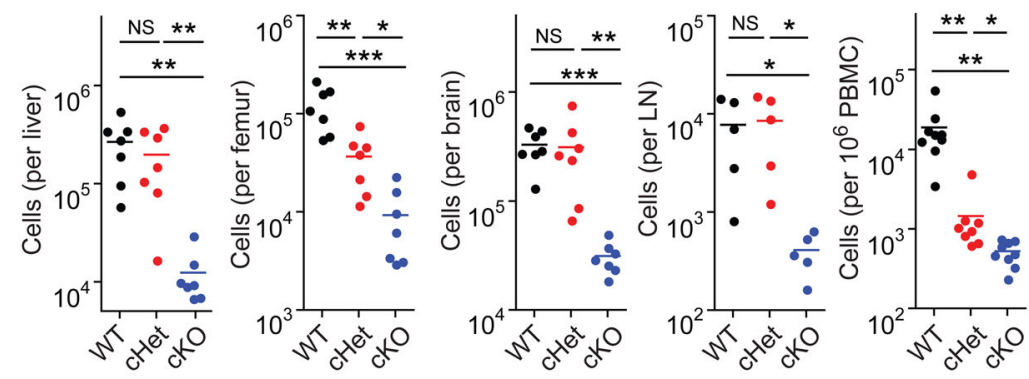

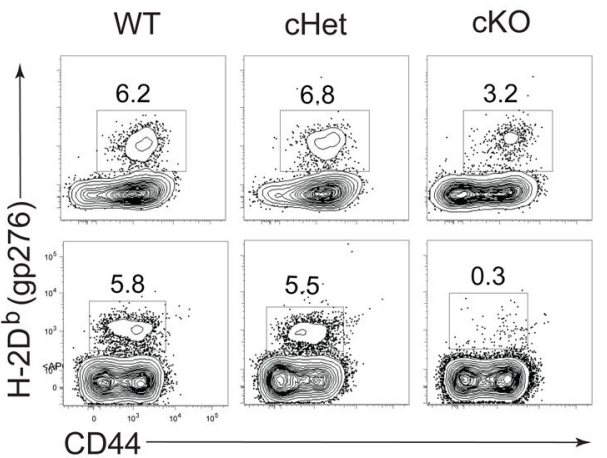

Day 30

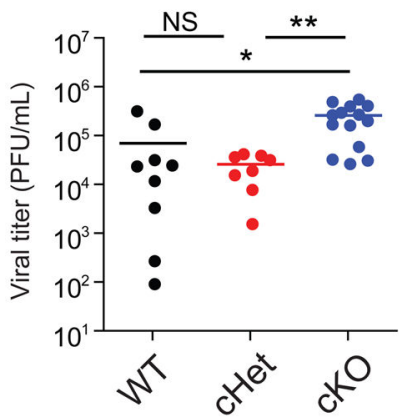

Figure 2. T-bet ablation results in loss of antigen-specific $\mathrm{CD8}^{+} \mathrm{T}$ cells and impairs viral control during chronic infection

(a) Frequency of $\mathrm{H}-2 \mathrm{D}^{\mathrm{b}}(\mathrm{gp} 33)$ (left) or $\mathrm{H}-2 \mathrm{D}^{\mathrm{b}}(\mathrm{gp} 276)$ (right) tetramer ${ }^{+} \mathrm{CD}^{+} \mathrm{T}$ cells in spleens from wild-type, cHet, and cKO mice at days 9 and 37 following clone 13 infection. (b,c) Numbers of gp276-specific $\mathrm{CD}^{+} \mathrm{T}$ cells in wild-type, cHet, and cKO mice at days 8 and 30 in spleens (b) and day 30 in indicated tissues (c) after clone 13 infection; numbers for bone marrow indicate gp276-specific CD8 T cells from one femur and for blood represent gp276-specific cells per million PBMC. (d) Longitudinal monitoring of viral titers from serum of wild-type, cHet, and cKO mice after clone 13 infection (error bars, S.E.M.). (e) Analysis of viral titers at day 30 p.i. Statistical analysis: NS, not significant $(P>0.05) ; * P<$ $0.05, * * P<0.005$, or $* * * P<0.001$ (two-tailed unpaired Student's $t$-test.). LN, lymph node; 
WT, wild-type (B6); cHet, Tbx2 $1^{\mathrm{fl} /+} \mathrm{CD} 4-\mathrm{Cre}$; cKO, Tbx2 $1^{\mathrm{fl} / \mathrm{fl} / \mathrm{CD} 4-C r e . ~ D a t a ~ s h o w n ~ a r e ~}$ representative of at least three independent experiments with at least 7 mice per group. 

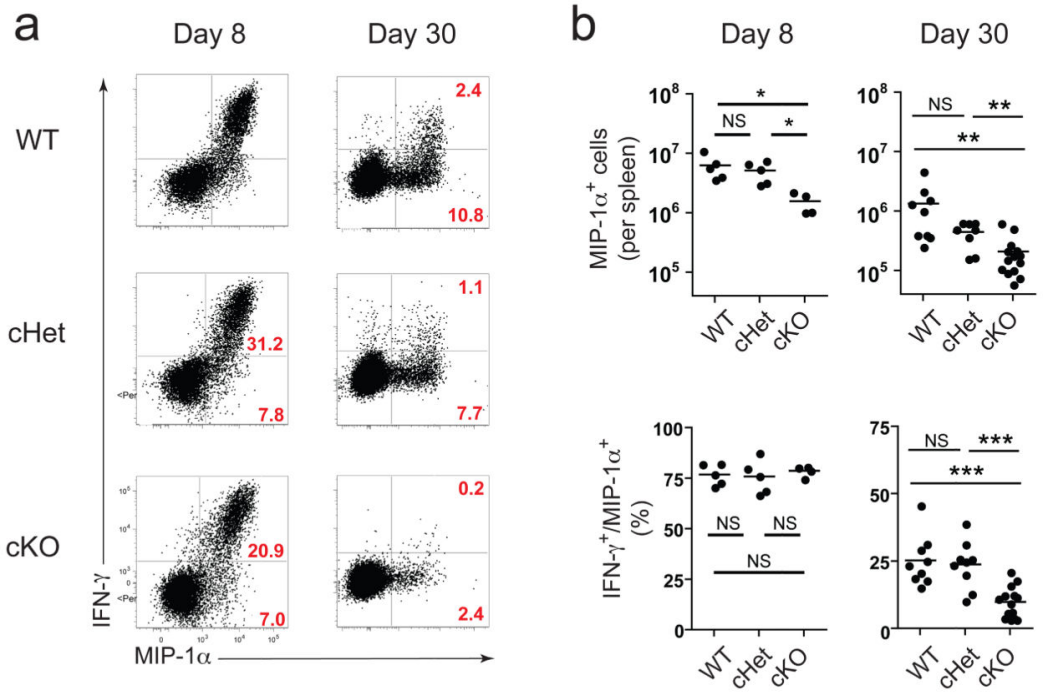

Figure 3. T-bet ablation impairs antigen-specific $\mathrm{CD8}^{+} \mathrm{T}$ cell function later but not early during chronic infection

(a) Representative dot plots showing IFN- $\gamma$ and MIP-1a production in $\mathrm{CD} 8^{+}$splenocytes from wild-type, cHet, and cKO mice restimulated with a pool of $20 \mathrm{LCMV}$-specific peptides at days 8 and 30 p.i. (clone 13); the percentages in red indicate percent IFN- $\gamma^{+}$MIP- $1 \mathrm{a}^{+}$ (top) and IFN- $\gamma^{-}$MIP-1 $1 \mathrm{a}^{+}$(bottom) relative to total CD8 ${ }^{+}$cells. (b) Total antigen-specific (i.e. MIP- $1 \mathrm{a}^{+}$) $\mathrm{CD}^{+} \mathrm{T}$ cells in spleen from wild-type, cHet, and cKO mice at day 8 (left) and day 30 (right) identified by peptide restimulation using gating strategy described in a (top graphs); percentages shown in bottom graphs indicate "polyfunctionality", i.e. percentage of total antigen-specific cells (MIP- $1 \mathrm{a}^{+}$) that are dual-positive (IFN- $\gamma^{+} /$ MIP- $\left.1 \mathrm{a}^{+}\right)$. Statistical analysis: NS, not significant $(P>0.05) ; * P<0.05, * * P<0.005$, or $* * * P<0.001$ (two-tailed unpaired Student's $t$-test.) WT, wild-type (B6); cHet, Tbx2 $1^{\mathrm{fl} 1 /+}$ $\mathrm{CD} 4-\mathrm{Cre} ; \mathrm{cKO}, T b \times 21^{\mathrm{fl} / \mathrm{fl}} \mathrm{CD} 4-\mathrm{Cre}$. Data are representative of at least three independent experiments with at least 4 mice per group. 
a

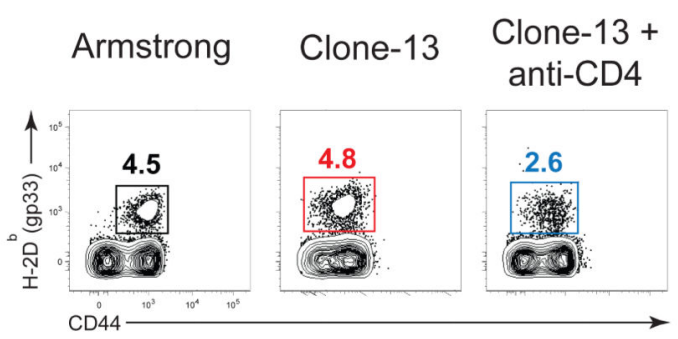

b

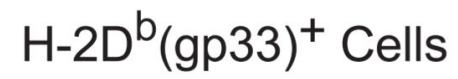

Day 8

Armstrong

Clone-13

Clone-13+
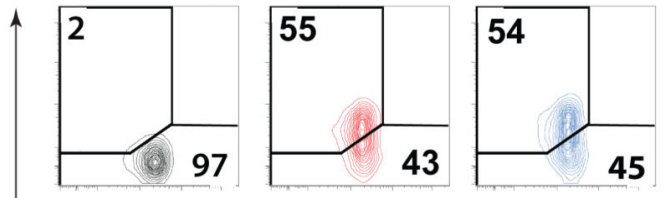

Day 26
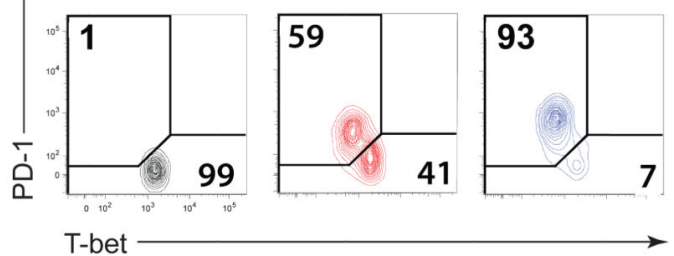

\section{C}

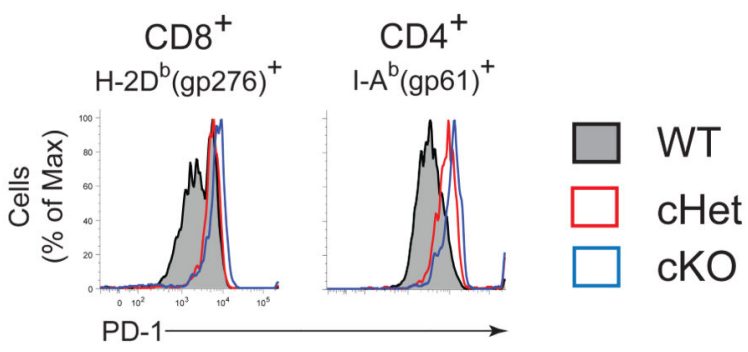

Figure 4. T-bet and PD-1 expression inversely correlates during chronic infection (a) Frequency of antigen-specific $\mathrm{CD} 8^{+}$cells within spleen of B6 mice infected with Arm or clone 13 (with or without CD4 depletion) on 26 p.i. (b) Costaining for intracellular T-bet and surface PD- 1 in antigen-specific $\left(\mathrm{D}^{\mathrm{b}} \mathrm{GP} 33^{+}\right) \mathrm{CD} 8^{+} \mathrm{T}$ cells at days 8 and 26 p.i. (c) $\mathrm{PD}-1$ expression on antigen-specific $\mathrm{CD} 8^{+}$and $\mathrm{CD}^{+}\left(\mathrm{I}-\mathrm{A}^{\mathrm{b}}(\mathrm{gp} 66)^{+}\right) \mathrm{T}$ cells in spleen from wildtype, cHet, and cKO mice at d30 p.i. (clone 13). WT, wild-type (B6); cHet, $T b x 21^{\mathrm{fl} / /+} \mathrm{CD} 4-$ $\mathrm{Cre}$; $\mathrm{cKO}, \mathrm{Tb} \times 21^{\mathrm{fl} / \mathrm{fl}} \mathrm{CD} 4-\mathrm{Cre}$. Data shown are representative of at least three independent experiments with at least 3 mice per group. 


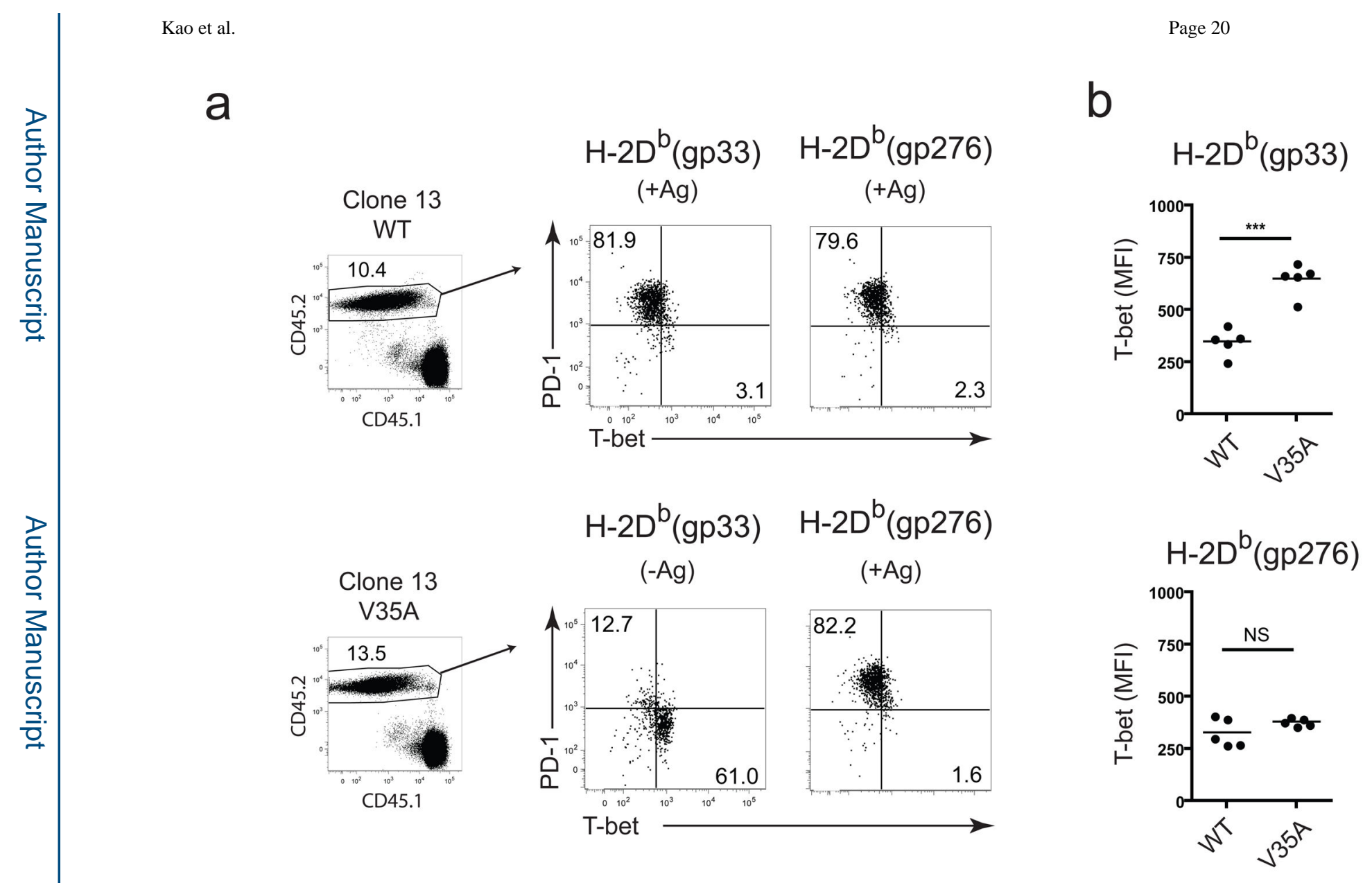

Figure 5. T-bet downregulation during chronic infection is due to persisting antigen (a) $\mathrm{CD}^{+}$splenocytes from clone 13 -infected donors (CD45.2 ${ }^{+}$) were adoptively transferred into congenic hosts infected with either wild-type or the V35A strain of clone 13 at d8 p.i., and expression of PD-1 and T-bet in donor gp33-specific and gp276-specific CD8 ${ }^{+} \mathrm{T}$ cells in the spleen 8 days after transfer is shown. (b) Quantitative analyses of T-bet expression in donor gp33- and gp276-specific $\mathrm{CD}^{+}$cells from a are displayed, where each data point represents an individual host. Statistical analysis: NS, not significant $(P>0.05)$; ** $P<$ 0.005 (two-tailed Student's $t$ test). WT, wild-type. Similar results were observed in two independent experiments with 4-6 mice per group. 
a

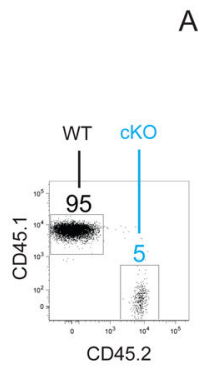

Armstrong
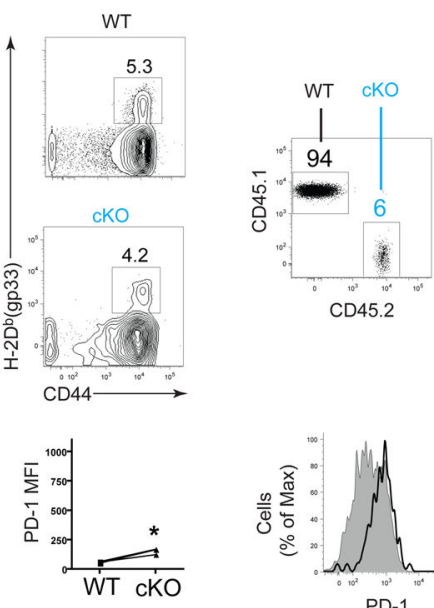

b

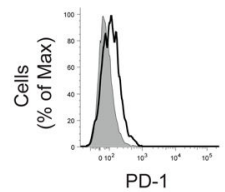

$\mathrm{H}-2 \mathrm{Db}(\mathrm{gp} 33)$
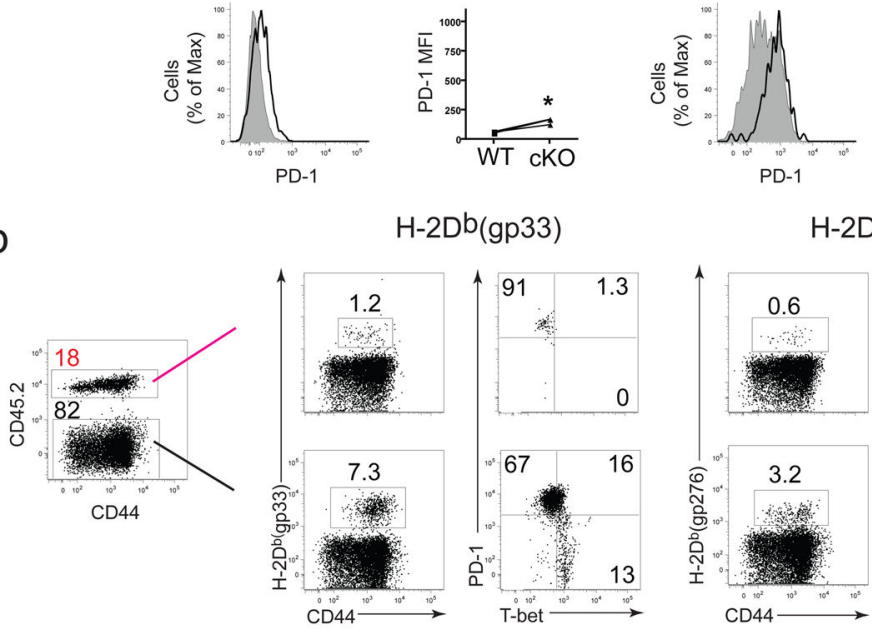

Clone 13
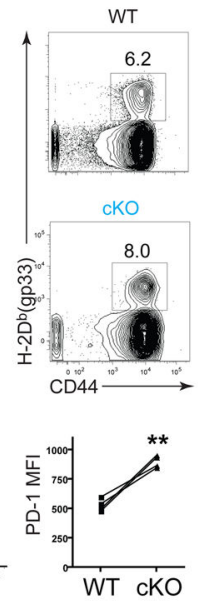

$\mathrm{H}-2 \mathrm{Db}(\mathrm{gp} 276)$

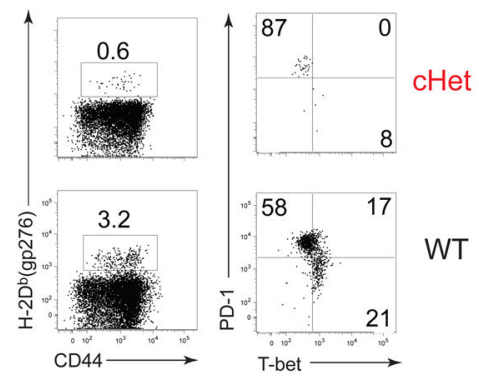

C

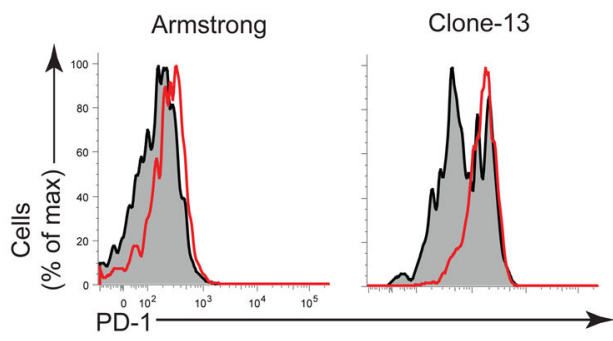

P14 WT

$\mathrm{P} 14 \mathrm{~Tb} \times 21^{+/-}$

Figure 6. Peripheral chimeras and mixed P14 transfers demonstrate a cell-intrinic role for T-bet repression of PD-1

Chimeras were generated by transferring (i.v.) $25 \times 10^{6} \mathrm{CD}^{+} \mathrm{T}$-bet cKO (a) or T-bet cHet (b) splenocytes into CD45.1 ${ }^{+}$wild-type hosts or transferring (i.v.) $1000 \mathrm{CD} 8^{+}$wild-type $\left(\mathrm{CD} 45.2^{+}\right)$and $1000 \mathrm{CD} 8^{+} \mathrm{Tb} x 21^{+/-}\left(\mathrm{CD} 45.1^{+} \mathrm{CD} 45.2^{+}\right)$into CD45.1 $1^{+}$wild-type hosts then infecting with LCMV the following day (c). (a) Hosts were bled on d8 p.i. and PD-1 expression on gated host and donor $\mathrm{CD}^{+}$gp33- or gp276-specific PBMCs were assessed. (b) T-bet and PD-1 expression of gated T-bet cHet donor (top panels) and wild-type host (bottom panels) antigen-specifc $\mathrm{CD} 8^{+}$splenocytes $\mathrm{d} 42$ p.i. (c) Overlay histograms showing PD-1 expression on donor wild-type and $T b x 21^{+/-} \mathrm{CD} 8^{+} \mathrm{P} 14$ splenocytes $\mathrm{d} 40$ p.i. in one representative animal (among at least three animals per experimental group) infected with Arm (left) or clone 13 (right). Statistical analysis (a,c): NS, not significant $(P>0.05)$; ${ }^{*} P<$ $0.05, * * P<0.005$, or $* * * P<0.001$ (two-tailed paired Student's $t$-test.). WT, wild-type (B6); 
cHet, $T b x 21^{\mathrm{fl} / /+} \mathrm{CD} 4-\mathrm{Cre}$; cKO, Tbx2 $1^{\mathrm{fl} / \mathrm{fl}} \mathrm{CD} 4-\mathrm{Cre}$. Similar results were observed in 2-4 independent experiments with at least 3 mice per group. 
a

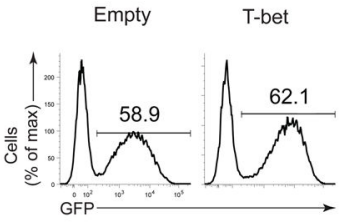

b
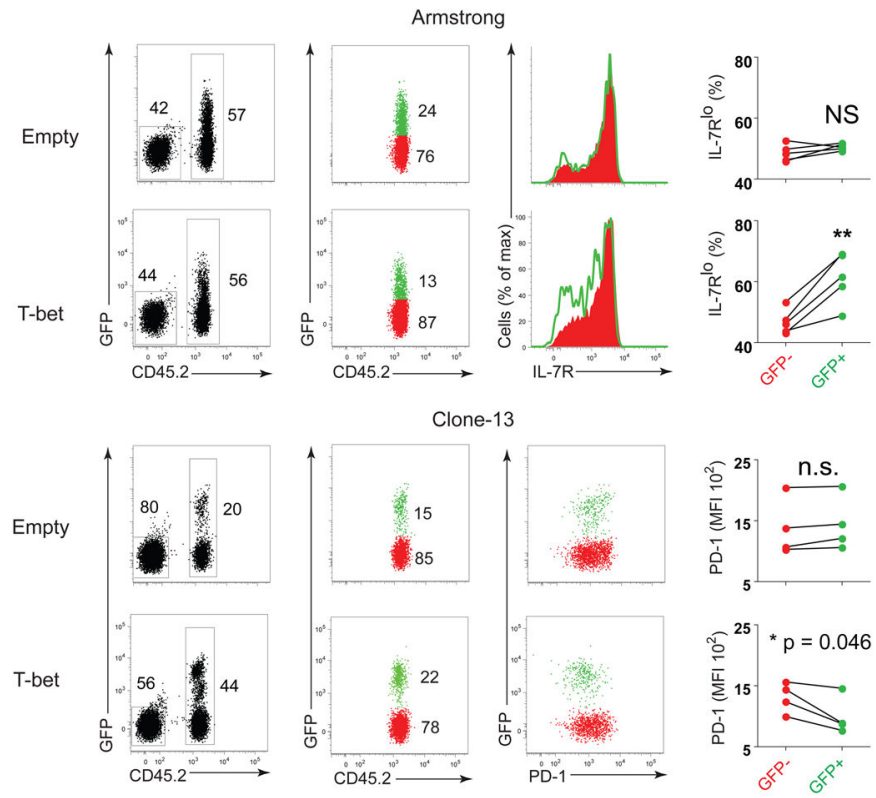

C
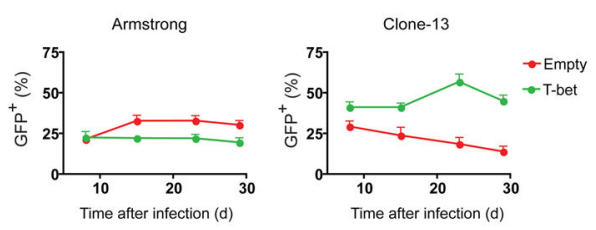

Figure 7. T-bet overexpression downregulates PD-1 expression and improves durability of exhausted antigen-specific $\mathrm{CD8}^{+} \mathrm{T}$ cells

Antigen-specific (P14 TCR transgenic) $\mathrm{CD}^{+} \mathrm{T}$ cells overexpressing T-bet (through retroviral transduction) were introduced into hosts infected with either LCMV Armstrong or clone 13. (a) Efficiency of transduction of $\mathrm{CD}^{+} \mathrm{P} 14$ cells was monitored in vitro 4 days post-activation (3 days post-transduction) when transduced with either empty (top) or T-bet expressing (bottom) retrovirus. (b) Splenocytes from Arm (top two rows) or clone 13 (bottom two rows) infected hosts were harvested on days 41-43 p.i.; donor P14 cells $\left(\mathrm{CD} 45.2^{+}\right)$were gated on $\mathrm{GFP}^{+}$or $\mathrm{GFP}^{-}$, and IL-7Ra or PD-1 expression on $\mathrm{GFP}^{+}$and $\mathrm{GFP}^{-} \mathrm{P} 14$ cells in Arm and clone 13 groups are shown; statistical analysis: NS, not significant $(P>0.05) ; * P<0.05$ or $* * P<0.005$ (two-tailed paired Student's $t$-test.) (d) Percentage of $\mathrm{GFP}^{+}$cells among transferred $\mathrm{P} 14$ population was tracked longitudinally from PBMC collected from Arm (left) or clone 13 infected hosts (error bars, s.e.m.). Similar results were observed in at least two independent experiments. 
a

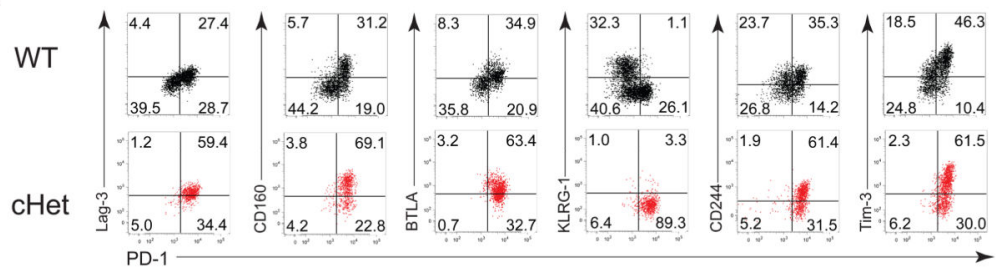

b
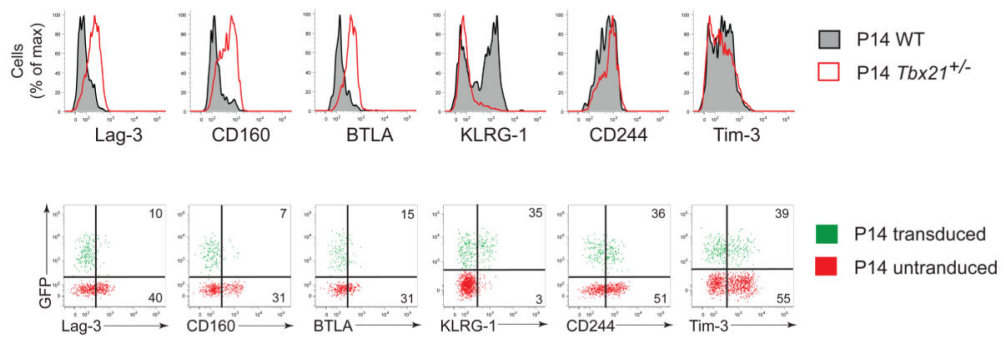

Figure 8. T-bet regulates expression of multiple cell-surface inhibitory receptors during chronic infection

(a) Same experiment as described for Fig 4c, except inhibitory receptor expression for wildtype (top row) and cHet (bottom row) are shown separately as dot plots in relation to PD-1.

(b) Same P14 mixed adoptive transfer strategy and color scheme for histograms as described for Fig 5d to compare expression of indicated inhibitory receptors between wild-type and Tbx $21^{+/-}$P14 in clone 13 infected hosts. (c) Same P14 retroviral overexpression and transfer strategy and gating strategy as described in Fig 6a,c; dot plots show inhibitory receptor expression on $\mathrm{GFP}^{+}$(transduced) and $\mathrm{GFP}^{-}$(untransduced) P14 cells in clone 13 infected hosts; percentages reflect those expressing inhibitory receptors among transduced (top) and untransduced (bottom) cells. Similar results were observed in at least 3 independent experiments with at least 3 mice per group. 
a

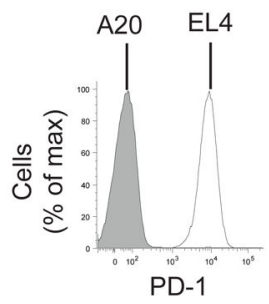

d
PMA +

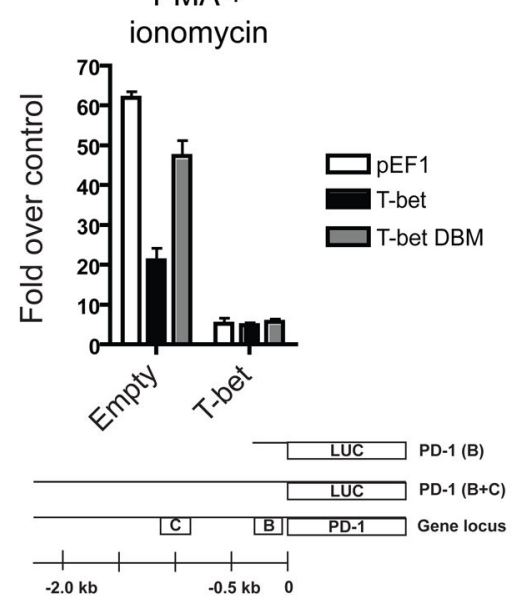

b

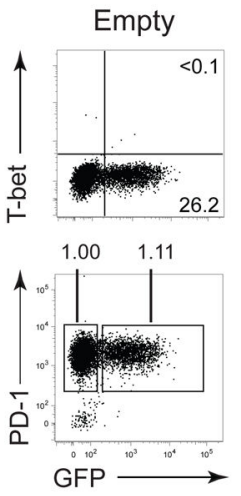

e

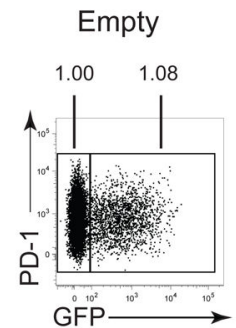

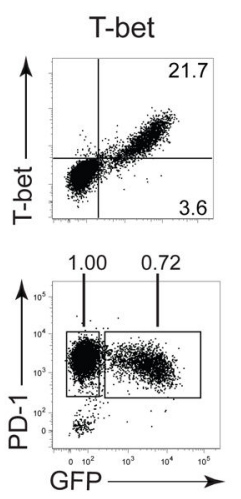

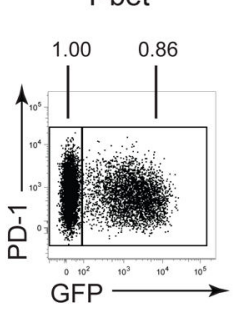

C

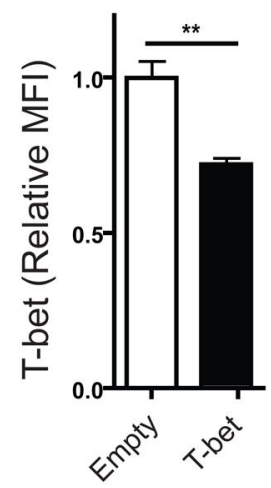

$f$

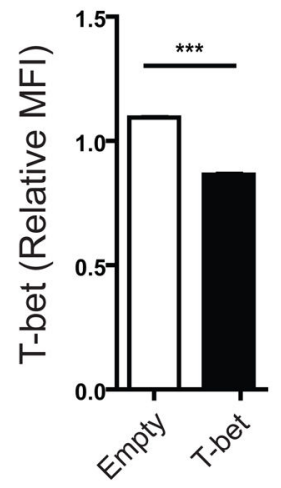

g

In vitro $\mathrm{P} 14$
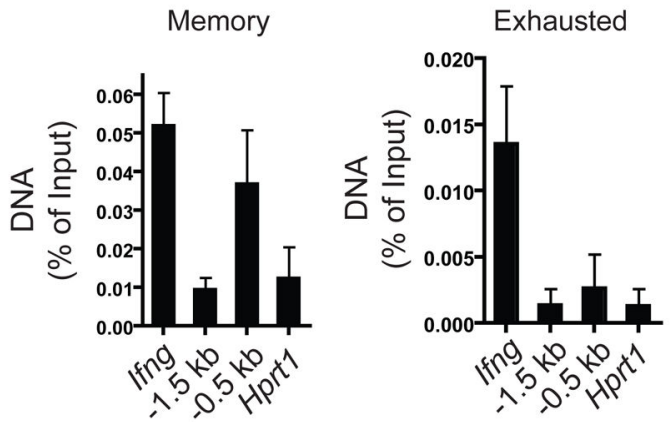

$\mathrm{h}$ In vitro $\mathrm{CD} 4 \mathrm{~T}_{\mathrm{H}^{1}}$

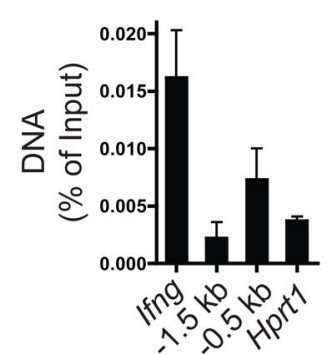

Figure 9. T-bet is a direct transcriptional repressor of the $P d c d 1$

(a-d) EL4 in vitro assays: (a) PD-1 expression on EL4 and A20 cells; representative plots of T-bet (left) and PD-1 (right) expression, $\mathbf{b}$, and statistical analysis of relative PD-1 expression, $\mathbf{c}$, after transduction with an empty retrovirus (top row) or T-bet retrovirus (bottom row); MFI was normalized to the untransduced (GFP-) population and indicated above the gates in $\mathbf{b} ;$ (d) schematic of PD-1 regulatory region containing two highly conserved regions (B and C) cloned into pGL3 luciferase reporter and luciferase activity of the PD-1 reporter when co-transfected with empty construct (pEF1) or one containing wildtype T-bet or T-bet DBM. (e,f) T-bet and PD-1 expession of CD8+ P14 cells activated in 
vitro and transduced with empty or T-bet retrovirus; representative plots, normalized MFI, and statistical analysis as described for $\mathbf{b}$ and $\mathbf{c}$. (g) T-bet ChIP of in vitro activated P14 TCR transgenic CD8+ splenocytes, P14 CD8+ T splenocytes d24 p.i. (Arm), and CD44hiCD62Llo CD8+ splenocytes (all PD-1Int or PD-1Hi) d40 p.i. (clone 13). PCR amplification of $-0.5 \mathrm{~kb}$ and $-1.5 \mathrm{~kb}$ regions of Pdcd 1 and promoter regions of Ifng and Hprt1. (h) T-bet ChIP of in vitro activated, $\mathrm{T}_{\mathrm{H}} 1$ polarized WT or $T b x 21^{-/-} \mathrm{CD} 4^{+} \mathrm{T}$ cells and qPCR of $P d c d 1$. Statistical analysis: $* * P<0.005$ (error bars, S.E.M; two-tailed Student's $t$ test). WT, wild-type; ChIP, chromatin immunoprecipitation. Similar results were observed in at least $2-5$ independent experiments. 